\title{
A Small Quarterly Projection Model of the US Economy
}

Ioan Carabenciov, Igor Ermolaev, Charles Freedman, Michel Juillard, Ondra Kamenik, Dmitry Korshunov, and Douglas Laxton 



\title{
IMF Working Paper
}

\author{
Research Department
}

\section{A Small Quarterly Projection Model of the US Economy ${ }^{1}$ \\ Prepared by Ioan Carabenciov, Igor Ermolaev, Charles Freedman, Michel Juillard, Ondra Kamenik, Dmitry Korshunov, and Douglas Laxton}

Authorized for distribution by Charles Collyns

December 2008

\begin{abstract}
This Working Paper should not be reported as representing the views of the IMF. The views expressed in this Working Paper are those of the author(s) and do not necessarily represent those of the IMF or IMF policy. Working Papers describe research in progress by the author(s) and are published to elicit comments and to further debate.

This is the first of a series of papers that are being written as part of a project to estimate a small quarterly Global Projection Model (GPM). The GPM project is designed to improve the toolkit for studying both own-country and cross-country linkages. In this paper, we estimate a small quarterly projection model of the U.S. economy. The model is estimated with Bayesian techniques, which provide a very efficient way of imposing restrictions to produce both plausible dynamics and sensible forecasting properties. After developing a benchmark model without financial-real linkages, we introduce such linkages into the model and compare the results with and without linkages.

JEL Classification Numbers: C51; E31; E52

Keywords: Macroeconomic Modeling; Bayesian Estimation; Monetary Policy Author's E-Mail Address: dlaxton@imf.org; icarabenciov@imf.org, okamenik@imf.org

\footnotetext{
${ }^{1}$ I. Ermolaev and D. Korshunov are affiliated with the Bank of Russia, C. Freedman with Carleton University, Ottawa, Canada, and M. Juillard with the Bank of France and CEPREMAP. The authors wish to thank Jeannine Bailliu, Patrick Blagrave, Olivier Blanchard, Jorge Canales, Don Coletti, Charles Collyns, Jörg Decressin, Roberto Garcia-Saltos, Marianne Johnson, Simon Johnson, Alin Mirestean, James Rossiter, Larry Schembri, Kadir Tanyeri and colleagues at other policymaking institutions for encouraging us to do this work. We also gratefully acknowledge the invaluable support of Heesun Kiem and Susanna Mursula in research assistance, and of Laura Leon in the preparation of this paper. The views expressed here are those of the authors and do not necessarily reflect the position of the International Monetary Fund. The DYNARE estimation programs used in this paper can be accessed from www.douglaslaxton.org. Correspondence: dlaxton@imf.org.
} 
Contents

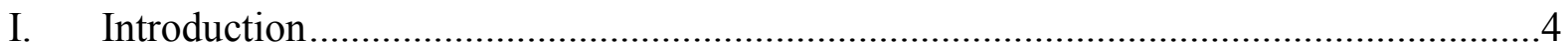

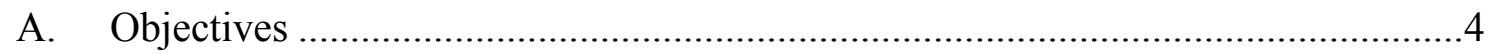

B. The US Economy Over the Sample Period............................................................4

II. Benchmark Model Without Financial-Real Linkages ............................................. 7

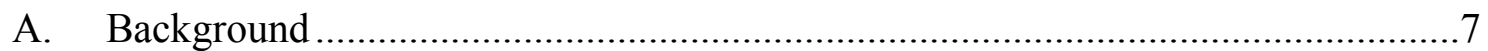

B. The Specification of The Model ......................................................................

B1. Observable variables and data definitiions ............................................... 9

B2. Stochastic processs and model definitions................................................

B3. Behavioral equations....................................................................... 10

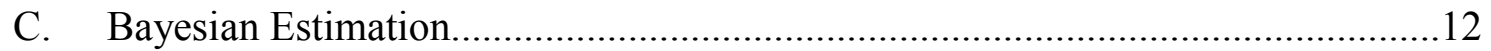

D. Confronting the Balanced Model with The Data ............................................13

III. Extended Model with Financial-Real Linkages...................................................15

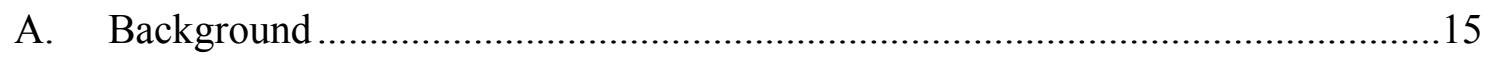

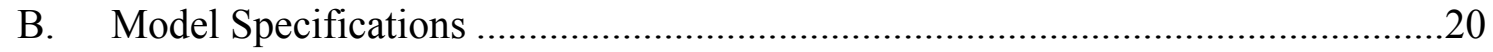

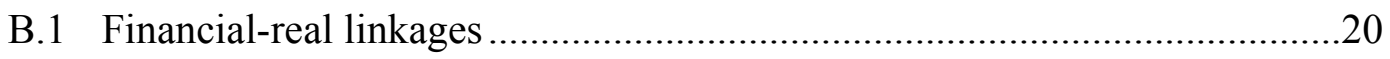

B2. Cross correlations of disturbances ........................................................22

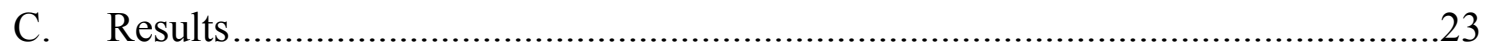

D. Some Extensions ...............................................................................25

D1. Comparison of results from long sample and short sample for Model with financial variable ......................................................25

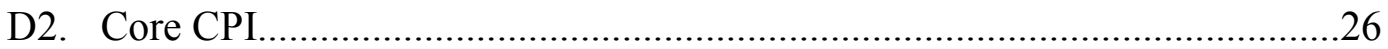

IV. Concluding Remarks.........................................................................................26

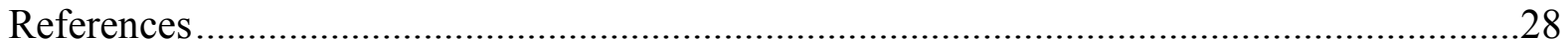

Appendix

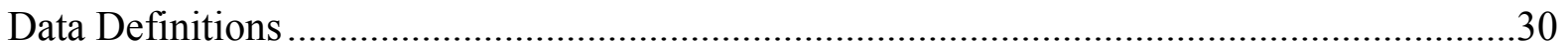

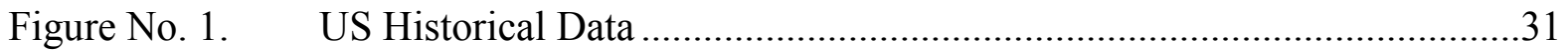

Table No. 1 Results from Posterior Maximization (parameters)

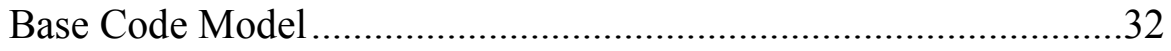

Table No. 2 Results from Posterior Maximization (standard deviation of structural Shocks) Base Case Model ..........................................33

Figure No. 2 Unemployment and Model-Consistent NAIRU ......................................34

Figure No. 3. GDP and Model-Consistent Potential GDP .............................................35

Table No. 3. Base Case Root Mean Squared Errors ....................................................36

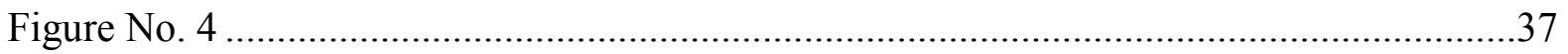


Table No. 4. Results from Posterior Maximization (parameters) BLT Model .38

Table No. 5. Results from Posterior Maximization (standard deviation of structural Shocks) BLT Model. 39

Table No. 6. Results from posterior parameters (correlation of structural shocks) BLT Model ...................................................................4 40

Figure No. $5 \quad$ IRF Supply Shock ...................................................................... 41

Figure No. 6 IRF Demand Shock........................................................................ 42

Figure No. 7 IRF Policy Rate Shock......................................................................43

Figure No. 8 IRF BLT Shock............................................................................44

Figure No. 9. IRF Equilibrium GDP Growth Shock ....................................................45

Figure No. 10 IRF Equilibrium GDP Level Shock.....................................................46

Table No. 7. BLT Root Mean Squared Errors ...............................................................47

Table No. 8. Variance Decompositions ....................................................................48

Figure No. 11. Y-O-Y GDP Growth Rate Dynamic Forecast (Base Case Model)...........49

Figure No. 12. Y-O-Y GDP Growth Rate Dynamic Forecast (BLT Model)....................49

Figure No. 13. Q-O-Q GDP Growth Rate Dynamic Forecast (Base Case Model)............50

Figure No. 14. Q_O_Q GDP Growth Rate Dynamic Forecast (BLT Model) ..................50

Figure No. 15. Inflation Dynamic Forecast (Base Case Model) ......................................51

Figure No. 16. Inflation Dynamic Forecast (BLT Model) ............................................51

Figure No. 17. Interest Rate Dynamic Forecast (Base Case Model) ..............................52

Figure No. 18. Interest Rate Dynamic Forecast (BLT Model) .......................................52

Figure No. 19. Unemployment Rate Dynamic Forecast (Base Case Model) ...................53

Figure No. 20. Unemployment Rate Dynamic Forecast (BLT Model) .............................53

Figure No. 21. Output GAP Dynamic Forecast (Base Case Model)..................................54

Figure No. 22. Output GAP Dynamic Forecast (BLT Model).........................................54 


\section{Introduction}

\section{A. Objectives}

This study has two parts. The first sets out a small quarterly projection model of the US economy to illustrate the way that such models can be used to understand economic developments. Such models can also be used to forecast future developments. This is preparatory to the next step in our research agenda, which is to develop a Small Quarterly Global Projection Model (GPM) that will integrate a series of small country models into a single global model. The second part of the study expands the US model to include financial-real linkages of the sort that have become prominent in recent years, both in the literature and in the economy. This will allow us to analyze the differences between models with and without such linkages and help us in developing a global model that includes such linkages in more than one country and across borders. One of the ultimate goals of the research program is to assess the relative importance of real cross-border linkages and financial cross-border linkages in bringing about the commonalities of the business cycle internationally. ${ }^{2}$

\section{B. The US Economy Over the Sample Period}

The model is estimated over two sample periods - 1994Q1 to 2008Q1 (the long period) and 2001Q1 to 2007Q4 (the short period). These two relatively short sample periods were chosen for a number of reasons. First, to simplify the estimation exercise we wanted to ignore changes in underlying inflation objectives and other structural changes in the economy that would have had to be dealt with over longer sample periods. Second, because some of the extended versions of the model (particularly the global version) will contain variables that are not available before these sample periods we wanted to restrict the estimation of the initial benchmark models that will be used as a basis for adding additional variables and countries. Third, we wanted to show that the use of priors can help deal with the problems associated with estimating models over short sample periods in cases where parameters will be weakly identified by the data. Fourth, as will be explained later, the role of financial variables seems to be considerably stronger in this

\footnotetext{
${ }^{2}$ Bayoumi and Swiston (2007) use VARs to try to achieve the same objective.
} 
decade than in previous decades, suggesting the use of the shorter period for estimation of the model with financial-real linkages.

Before moving to the model and estimation results, it will be useful to review some of the key developments in the US economy over the period under study, in particular the types of shocks (supply or demand) that buffeted the economy as well as the changes in the policy interest rate in response to these shocks and to other concerns. A brief description of these developments will be helpful in assessing the extent to which the model is able to capture the economic and policy movements over the period. Figure 1 sets out the key variables for the US economy over the 1990-2007 period.

In 1994, as the economy completed its recovery from the recession of 1990-1991 and as concerns began to grow about inflationary pressures, the Fed raised its policy interest rate towards a more neutral, less stimulative level. Some have argued that these actions were crucial in permitting the subsequent economic expansion to be so long lasting. Over the period 1996 to 1999, the economy continued to grow at a fairly rapid pace, with unemployment falling to levels that had not been seen in decades. There was considerable concern that the levels of both output and unemployment were in the range of excess demand and would lead to inflationary pressures, and that the appropriate policy response to prevent these inflationary pressures from developing would be to raise interest rates. In contrast, the Federal Reserve (and especially Chairman Greenspan) argued that the spread of computer-based technology was a positive supply shock to the US economy, which was leading to an increase in the potential growth rate of the economy. ${ }^{3}$ At the same time, it appeared that the NAIRU had declined from the widely accepted $6 \%$ range to $5 \%$ or perhaps even somewhat lower. Among the explanations offered for this development were improved matching of workers and jobs, the legal and illegal immigration that increased the supply of labor and prevented bottlenecks from developing, and the rapid growth of the Chinese and Southeast Asian economies, which reduced the bargaining strength of labor in the United States and permitted the decline in unemployment to occur without excessive pressure on wages and prices.

Towards the end of the decade, there were increased concerns about inflationary pressures, as the level of demand was perceived to be high even relative to the increased potential, as the increase in oil prices fed into the headline CPI and raised fears that it would affect inflation expectations,

\footnotetext{
${ }^{3}$ See Meyer (2000) for a discussion of the dynamics resulting from this type of shock, which not only reduced inflation pressures but also increased aggregate demand as the expected higher productivity growth led to increases in stock market values and higher perceived permanent incomes.
} 
and as core CPI (defined for our purposes as the CPI excluding food and energy) also displayed an upward tendency. In response, the Fed began to raise interest rates gradually through 1999 and into 2000. GDP growth slowed appreciably from about mid-2000, partly in response to the high-tech slowdown and the weakness in the stock market, and inflation responded with a sharp decline from about mid-2001. Both developments began before 9/11, but the uncertainty generated by the terrorist attacks accentuated the ongoing weak demand, and it also raised concerns about whether there would be even more weakness than in fact occurred. The Fed gradually reduced its policy interest rate to levels that had not been seen since the early 1960s. Moreover, with the decline of inflation to very low levels (on the order of about $1 \%$ in year-on-year headline CPI in mid-2002 and in year-on-year core CPI in late 2003), the dominant fear became one of deflation, of the sort that had weakened the Japanese economy for almost a decade. The Fed's response was to lower the fed funds rate to $1 \%$ in mid-2003 and to commit itself to hold the rate at very low levels until the risk of deflation dissipated. Starting in mid-2004, the Fed began to remove the monetary stimulus provided by the prevailing low interest rates by gradually raising interest rates back towards more neutral levels. This was also the period of the "interest rate conundrum", the term coined by Chairman Greenspan to describe the fact that long-term real interest rates remained low in the face of the significant increase in short-term nominal and real interest rates. The period of low policy interest rates was successful in reinvigorating the economy (with continuing strong residential construction expenditures and other consumer-led expenditures in which the housing price boom played an important role) and causing unemployment to decline from a peak of about $6 \%$ in 2003 to a trough of about $41 / 2 \%$ in 2006. Finally, over the past few months, the end of the housing price boom, the inability of many homeowners who had borrowed in the subprime mortgage market to maintain their mortgage payments as interest rates rose and house prices fell, the liquidity problems in the asset-backed commercial paper market, and the problems faced by holders of structured financial instruments have together led to considerable weakness in demand in the United States and another round of easing by the Fed.

The challenge for any model trying to describe the behavior of the American economy over this period is to replicate the combination of supply and demand shocks, the policy responses to these shocks, and the dynamics of the economy in a way that helps explain the actual movements in output, inflation, and interest rates. Of course, the small model that we will be presenting in the next section will not be able to pick up some of the recent financial shocks that have buffeted the US economy, since the financial sector of the model is very rudimentary. However, the addition of 
financial variables to the basic model in the subsequent section will help capture some of the recent developments in the US economy. In practice, the key question is whether the estimates of shocks in either the basic model or the extended model are plausible over the sample period and if they can end up adequately replicating the behavior of the economy in the face of such shocks.

\section{Benchmark Model Without Financial-Real Linkages}

\section{A. Background}

In recent years, the IMF has developed two types of macroeconomic models - dynamic stochastic general equilibrium (DSGE) models and small quarterly projection models - that it has used to analyze economic behavior and to forecast future developments. The DSGE models are based on theoretical underpinnings and have been found to be very useful in analyzing the effects of structural changes in the economy, as well as the effects of longer-term developments such as persistent fiscal deficits and current account deficits. ${ }^{4}$ And multi-country variants of these models have allowed researchers to analyze the effects of shocks in one country on economic variables in other countries. The small quarterly projection models use four or five behavioral equations to characterize the macroeconomic structure of an economy in a way that is both easy to use by modelers and comprehensible to policymakers. They focus on the key macroeconomic variables in the economy - typically output, inflation, a short-term interest rate, and sometimes the exchange rate and/or the unemployment rate. By virtue of their relatively simple and readily understandable structure, they have been used for forecasting and policy analysis purposes in central banks and by country desks in the IMF. ${ }^{5}$ In the past, the parameters of such models have been calibrated on the basis of the knowledge of country experts of the economic structure of the country being studied and that of similar countries.

\footnotetext{
${ }^{4}$ See Botman and others (2007) for a summary of the applications using these models.

${ }^{5}$ See Berg, Karam, and Laxton (2006a,b) for a description of the basic model as well as Epstein and others (2006) and Argov and others (2007) for examples of applications and extensions. Currently, there are several country desks at the Fund using the model to support forecasting and policy analysis and to better structure their dialogue with member countries. A number of inflation-targeting central banks have used similar models as an integral part of their Forecasting and Policy Analysis Systems - see Coats, Laxton and Rose (2003) for a discussion about how models are used in inflation-targeting countries,
} 
In this and subsequent papers, two important extensions will be made to the basic model. First, in this paper, Bayesian techniques are used to estimate the parameters of a version of the model for the US economy. Bayesian methods allow researchers to input their priors into the model and then to confront them with the data, in order to determine whether their priors are more or less consistent with the data. Although regime shifts in recent years (most notably, the anchoring of inflation expectations to a formal or informal target in many countries) limit the time series to relatively short periods, the approach taken in this paper will be increasingly useful over time as the lengths of usable time series are extended.

Second, in subsequent papers, the small quarterly models of a number of countries (U.S., the Euro area, Japan, emerging Asia, oil-exporting countries, Canada, Russia, and a remaining-country bloc) will be integrated into a small quarterly Global Projection Model (GPM), which will enable researchers to analyze the effects on a number of countries of shocks in one country and of global shocks. They will also give forecasters a new tool to assist them in preparing worldwide forecasts and in carrying out alternative policy simulations in the global context. There is strong demand for such an empirically based multi-country model, both for IMF surveillance work and for helping central bank forecasters to assess the external environment in preparing their projections. Large-scale DSGE models show promise but we are years away from developing empirically-based multicountry versions of these models. While global VARs (GVARs) have been developed for forecasting exercises they are not very useful for policy analysis because they lack the identification restrictions necessary to obtain plausible impulse response functions.

\section{B. The Specification of The Model}

We now consider a small generic closed economy model that describes the joint determination of output, unemployment, inflation, and the federal funds rate. A number of definitions and identities complete the model. 


\section{B.1 Observable variables and data definitions}

The benchmark model has only 4 observable variables. ${ }^{6}$ These are real GDP, the unemployment rate, CPI inflation (headline or core), and the federal funds rate. We define Y as 100 times the log of real GDP, $\bar{Y}$ as 100 times the log of potential output and lowercase $y$ as the output gap in percentage terms $(y=Y-\bar{Y})$. Similarly, we define the unemployment gap, $u$, as the difference between the actual unemployment rate $(U)$ and the equilibrium unemployment rate or NAIRU, $\bar{U}$. We define the quarterly rate of inflation at annual rates $(\pi)$ as 400 times the first difference of the $\log$ of the CPI. In addition, we define the year-on-year measure of inflation $(\pi 4)$ as 100 times the difference of the log of the CPI in the current quarter from its value four quarters earlier.

\section{B.2 Stochastic processes and model definitions}

A major advantage of Bayesian methods is that it is possible to specify and estimate fairly flexible stochastic processes. In addition, unlike classical estimation approaches, it is possible to specify more stochastic shocks than observable variables, which is usually necessary to prevent the model from making large and systematic forecast errors over long periods of time. For example, an important ingredient for a forecasting model is allowing for permanent changes in the underlying estimates of the equilibrium values for potential output and the equilibrium unemployment rate.

We assume that there can be shocks to both the level and growth rate of potential output. The shocks to the level of potential output can be permanent, while the shocks to the growth rate can result in highly persistent deviations in potential growth from long-run steady-state growth. In equation $1 \overline{\mathrm{Y}}$ is equal to its own lagged value plus the quarterly growth rate $(\mathrm{g} \bar{Y} / 4)$ plus a disturbance term $\left(\varepsilon^{\bar{Y}}\right)$ that can cause permanent level shifts in potential GDP.

$$
\bar{Y}_{t}=\bar{Y}_{t-1}+g_{t}^{\bar{Y}} / 4+\varepsilon_{t}^{\bar{Y}}
$$

As shown in equation 2 , in the long run the growth rate of potential GDP, $\mathrm{g}^{\bar{Y}}$, is equal to its steady-state rate of growth, $\mathrm{g}^{\bar{Y} s s}$. But it can diverge from this steady-state growth following a positive or negative value of the disturbance term $\left(\varepsilon^{g^{\bar{Y}}}\right)$, and will return to $\mathrm{g}^{\bar{Y} s s}$ gradually, with the

\footnotetext{
${ }^{6}$ Data definitions are provided in the appendix to this paper.
} 
speed of return based on the value of $\tau$.

$$
g_{t}^{\bar{Y}}=\tau g^{\bar{Y} s s}+(1-\tau) g_{t-1}^{\bar{Y}}+\varepsilon_{t}^{g^{\bar{Y}}}
$$

A similar set of relationships holds for the equilibrium or NAIRU rate of unemployment. $\bar{U}$ is defined in equation 3 as its own past value plus a growth term $\mathrm{g}^{\bar{U}}$ and a disturbance term $\left(\varepsilon^{\bar{U}}\right)$. And in equation $4, \mathrm{~g}^{\bar{U}}$ is a function of its own lagged value and the disturbance term $\left(\varepsilon^{g^{\bar{U}}}\right)$. Thus, the NAIRU can be affected by both level and persistent growth shocks.

$$
\begin{gathered}
\bar{U}_{t}=\bar{U}_{t-1}+g_{t}^{\bar{U}}+\varepsilon_{t}^{\bar{U}} \\
g_{t}^{\bar{U}}=\left(1-\alpha_{3}\right) g_{t-1}^{\bar{U}}+\varepsilon_{t}^{g^{\bar{U}}}
\end{gathered}
$$

Equation 5 defines the real interest rate, rr, as the difference between the nominal interest rate, rs, and the expected rate of inflation for the subsequent quarter.

$$
r r_{t}=r s_{t}-\pi_{t+1}
$$

Equation 6 defines rrgap, the real interest rate gap, as the difference between rr and its equilibrium value, $\overline{r r}$.

$$
\operatorname{rrgap}_{t}=r r_{t}-\overline{r r}_{t}
$$

Equation 7 defines $\overline{r r}$, the equilibrium real interest rate, as a function of the steady-state real interest rate, $\overline{r r}^{s s}$. It has the ability to diverge from the steady state in response to a stochastic $\operatorname{shock}\left(\varepsilon^{\bar{r}}\right)$.

$$
\overline{r r}_{t}=\rho \overline{r r}^{s s}+(1-\rho) \overline{r r}_{t-1}+\varepsilon_{t}^{\overline{r r}}
$$

\section{B.3 Behavioral equations}

Equation 8 is a behavioral equation that relates the output gap (y) to its own lead and lagged values, lagged values of the gap in the short-term real interest rate (rrgap), and a disturbance term $\left(\varepsilon_{t}^{y}\right)$.

$$
y_{t}=\beta_{1} y_{t-1}+\beta_{2} y_{t+1}-\beta_{3} \operatorname{rrgap}_{t-1}+\varepsilon_{t}^{y}
$$

All variables in this equation are expressed as gaps or deviations from their equilibrium values. The own-lag term allows for the inertia in the system, and also permits shocks to have persistent 
effects. The lead term allows more complex cycle dynamics and forward-looking elements in aggregate demand. The real interest rate term provides the crucial link between monetary policy actions and the economy.

Equation 9 is the inflation equation, which links inflation to its past value and its future value, the lagged output gap, and a disturbance term $\left(\varepsilon^{\pi}\right)$. The size of $\lambda_{1}$ measures the relative weight of forward-looking elements and backward-looking elements in the inflation process. The backward-looking elements include direct and indirect indexation to past inflation and the proportion of price setters who base their expectations of future inflation on actual past rates of inflation. The forward-looking element relates to the proportion of price setters who base their expectations on model-consistent estimates of future inflation. Because the residual enters the equation with a negative sign, the shock to the residual in the impulse response functions that will be presented later in this paper will be treated as a shock that results in downward pressure on the rate of inflation.

$$
\pi_{t}=\lambda_{1} \pi 4_{t+4}+\left(1-\lambda_{1}\right) \pi 4_{t-1}+\lambda_{2} y_{t-1}-\varepsilon_{t}^{\pi}
$$

Equation 10 is a Taylor-type equation that determines the short-term nominal interest rate (which can be interpreted either as the policy rate, as we do in this paper, or as a short-term market rate that is closely linked to the policy rate). It is a function of its own lag (a smoothing device for the movement of short-term rates) and of the central bank's policy responses to movements of the output gap and the deviation of the expected inflation rate from its target. More precisely, the central bank aims at achieving a measure of the equilibrium nominal interest rate over the long run (the equilibrium real interest rate and expected inflation over the four quarters starting the previous quarter), but adjusts its rate in response to deviations of the expected year-on-year rate of inflation three quarters in the future from the inflation target $\pi^{t a r}$ and to the current output gap. ${ }^{7}$ The equation also includes a disturbance term $\left(\varepsilon^{r s}\right)$ to allow for discretionary policy actions.

$$
r s_{t}=\left(1-\gamma_{1}\right)\left[\overline{r r}_{t}+\pi 4_{t+3}+\gamma_{2}\left(\pi 4_{t+3}-\pi^{t a r}\right)+\gamma_{4} y_{t}\right]+\gamma_{1} r s_{t-1}+\varepsilon_{t}^{r s}
$$

Equation 11 provides a dynamic version of Okun's law where the unemployment gap is a function

\footnotetext{
${ }^{7}$ The use of the rate of inflation three quarters in the future follows Orphanides (2003). We also experimented with the change in the output gap in the reaction function, but it did not make a significant difference overall and consequently was dropped from the specification.
} 
of its lagged value, the contemporaneous output gap and a disturbance term $\left(\varepsilon^{u}\right)$.

$$
u_{t}=\alpha_{1} u_{t-1}+\alpha_{2} y_{t}+\varepsilon_{t}^{u}
$$

This last equation does not play a fundamental role in the model but is used to help measure the output gap in real time by exploiting the correlation between changes in the output gap and future changes in the unemployment gap.

\section{Bayesian Estimation}

Bayesian estimation provides a middle ground between classical estimation and the calibration of macro models. The use of classical estimation in a situation of a relatively small sample size (which is almost always the case for time series data) often gives model results that are strange, and are inconsistent with the views of macroeconomists as to the functioning of the economy. This problem is accentuated by the simultaneity challenges to macro models, which are not handled well by simultaneous equation methods in small samples. For example, because an aggregate demand shock can lead to persistent inflationary pressures and to central bank actions to raise interest rates to offset the shock, classically estimated models using time series data will sometimes show an increase in interest rates leading to an increase in inflation. This is particularly problematic when the model is to be used for policy simulations, since it may well indicate the need for an interest rate decline to slow the rate of inflation.

Models with calibrated parameters avoid this problem, but are often criticized as representing no more than the modelers' judgment, which may or may not be consistent with the data. While calibration is typically based on the understanding of experts of the functioning of the economy, the desire to confront the model with the data in a statistical sense has led researchers to use Bayesian estimation techniques to estimate models.

The Bayesian approach has the benefit of putting some weight on the priors of the researchers and some weight on the data over the sample period. By specifying the tightness (e.g., the standard deviation) of the distribution on the priors, the researcher can change the relative weights on the priors and the data in determining the posterior distribution for the parameters. In the limit, a diffuse or noninformative distribution puts more weight on the data while a distribution with a 
very tight prior distribution (e.g., a small standard deviation) puts more weight on the priors.

There are a number of criteria by which researchers evaluate the success of Bayesian estimated models and decide between models with different weights placed on priors and the data. First, if an estimated model yields coefficients that are close to the priors in spite of allowing considerable weight to be placed on the data, it indicates that the priors are not inconsistent with the data. A second criterion involves seeing whether the impulse response functions from the model estimated with Bayesian techniques are compatible with the views of the researchers (and in the case of models built at central banks with the views of the management of the central bank) with respect to the functioning of the economy in response to shocks. Third, in comparing different variants of a given macro model (for example, one that treats shocks to output as largely demand determined and another that treats shocks as largely supply determined), researchers can use the relative magnitudes of the log data density and root mean squared errors (RMSEs) as indications of which model is more consistent with the data.

Bayesian estimated models are likely to have better model properties than classically estimated models, but may sometimes not fit the data as well as simple VAR models, since the sole purpose of the latter is to maximize fit. It is the combination of reasonable fit, appropriate structural results from a theoretical perspective, and the ability to give sensible results for policy simulations that gives estimated Bayesian models their strength. Also, the use of such models along with judgmental inputs for the first two quarters of the forecast period is likely to give better and more sensible forecasting results than most other models. A comparison of Bayesian-estimated Global Projection Models with competitor global models will be presented in the future paper.

\section{Confronting the Balanced Model with The Data}

Given our understanding of the developments in the US economy over the sample period, with both demand and supply shocks contributing to movements in output, unemployment, and inflation, it seems reasonable for the analysis to use a balanced version of the model that treats both kinds of shocks as important. ${ }^{8}$ Table 1 sets out estimation results for the parameters in the

\footnotetext{
${ }^{8}$ We have compared three variants of the full model - a demand variant, a supply variant, and the balanced variant used in the analysis in the text. By the choice of priors on the the standard errors of the disturbance terms in the various equations, movements of the model variables can be treated as coming largely from demand shocks (the demand-side model), as coming largely from supply shocks (the supply-side model), or as coming from a world in which both
} 
model, showing the distribution used in the estimation, the prior mean, the prior standard deviation, the posterior mode, and the posterior standard deviation. The posterior coefficients in the output gap equation put more weight on both the lagged output gap and the lead of the output gap, but less weight on the real interest rate than the prior coefficients. In the inflation equation, the posterior coefficients put considerably less weight on the backward-looking element and considerably more weight on the forward-looking element than the prior coefficients. There is also somewhat less weight on the output gap in the inflation equation than in the priors. As far as the interest rate equation is concerned, the estimated weight on the inflation gap is somewhat lower and on the output gap is slightly higher than in the priors, but the estimated smoothing coefficient is considerably stronger than in the priors. In the unemployment gap equation, the posterior coefficient on the output gap is appreciably smaller than the prior. There is also higher-than-expected persistence of the growth term in the NAIRU equation.

Table 2 presents the same information for the standard deviation of the structural shocks, making use of more diffuse priors. For the standard deviations of structural shocks in the equations relating to unemployment (the unemployment rate, the level and the growth rate of NAIRU) and those in the equations relating to the interest rate (the federal funds interest rate and the equilibrium real interest rate), the posteriors are considerably smaller than the priors. For the inflation equation and for two of the three equations relating to output (the output gap and the growth rate of potential output), the posteriors are substantially higher than the priors. The posterior of the standard deviation of the shock in the third output equation (the level of potential output) is considerably smaller than the prior. These results indicate that, compared to prior expectations, there is considerably less uncertainty about the shock terms pertaining to unemployment and interest rates and considerably more about those pertaining to inflation and output.

How well do the results of this version of the model match the data over the sample period 1994 to 2007? The model shows a decline in the NAIRU in the second half of the 1990s, from just above $6 \%$ to just above $41 / 4 \%$, followed eventually by an increase to above $41 / 2 \%$ (figure 2 ). It also shows some pickup in potential growth in the second half of the 1990s and a slowing thereafter, with excess demand in much of the former period and excess supply in much of the

demand and supply shocks play a prominent role (the balanced model). We have also compared the results from the full four equation model with those from univariate and bivariate models of the output gap and the unemployment gap. For access to the code for all of these cases see www.douglaslaxton.org. The web site also provides examples using maximum likelihood estimation to show why classical estimation procedures break down in small samples. 
latter (figure 3). Overall, the base model has satisfactory impulse response functions (not shown). Table 3 shows the model's intra-sample RMSEs, which have been created without adding any judgmental input. Since central bank actions (as shown by the reaction function) have succeeded in anchoring inflation and inflation expectations close to underlying inflation objectives over the sample period, the model will have difficulty generating a downturn in the absence of a breakout of inflation. While the impulse response functions suggest that the structure of endogenous equations is not unreasonable, it appears necessary to add another element to the model to provide it with better dynamics and the ability to generate a downturn under certain circumstances. Given recent developments, a financial variable would seem to be an appropriate addition to the model. In the next section such a financial variable is used to provide more dynamics and leading indicator properties, and potentially better forecasting ability in the model.

\section{Extended Model With Financial-Real Linkages}

\section{A. Background}

For much of the postwar period, downturns in business cycles were precipitated mainly by increases in policy interest rates initiated by central banks in response to periods of excess demand that gave rise to inflation pressures. Indeed, in some countries (the United Kingdom being a prominent example), actions of the fiscal and monetary authorities were considered to have brought about a stop-go economy, in which the policy switched periodically back and forth between an emphasis on unemployment and economic growth, on the one hand, and an emphasis on inflation, on the other. When the economy was weak, policy eased, giving rise to expansionary pressures. When these pressures were sufficiently strong and inflation became the overriding concern, policy was tightened so that the slowing or contraction of the economy would put downward pressure on inflation and prevent it from getting out of hand.

Such policy-induced slowdowns of the economy persisted from the 1950s into the 1990s, with virtually every downturn preceded by inflationary pressures and a resulting tightening of monetary policy. However, this central bank tightening explanation cannot account for the economic slowdown of the early part of this decade, or of the current slowdown in the US and other economies, since inflation pressures and interest rate increases were evidently not the main 
reason for these downturns. In the context of the apparent linkages between financial developments and the real economy, driven in part through asset price movements, attention has increasingly turned to the ways in which financial developments can affect the real economy. This interest has been aided by the development of theoretical models to describe and explain these linkages, in particular the financial accelerator mechanism. ${ }^{9}$

In our view, the more traditional types of models that allow central bank actions to play a major role in business cycle developments are needed to explain much of the postwar period. However, the developments over the last decade or so require an extension to those models that have placed central bank actions at the center of the business cycle (and particularly in the downturns). The key factors in these most recent developments, and to a much lesser extent in earlier developments, are the financial developments that have interacted with the real side of the economy in what has come to be called financial-real linkages.

There are many different variants of financial-real linkages. Some refer to developments in financial institutions, while others focus on developments in financial markets. Within the financial institution sector, some relate to the behavior of banks and other financial institutions in dealing with perceptions of the changing risk situation facing their customers or changing attitudes to risk on their own part, while others relate to situations in which banks' capital positions have deteriorated. In the case of financial markets, there have been cases in which liquidity has seized up and prevented potential borrowers from issuing debt, and other cases in which actual or perceived pressures on the balance sheets of lenders and/or borrowers have been the origin of the inability of the financial markets to carry out their normal intermediation functions.

These different variants can be seen in economic episodes in which the financial-real linkages make themselves felt. In normal times financial accelerators may help to explain movements in spending, but interest rate movements can typically capture most of the effects of the accelerators. It may only be in "abnormal" times that the behavior on the financial side is such as to require special treatment to pick up its effects.

What are the episodes that require special treatment? If one goes back sufficiently far into the

\footnotetext{
${ }^{9}$ See, for example, Bernanke and Gertler (1995). Interestingly, the perceived structural change in the way the economy operates has given rise to renewed interest in models of the business cycle from the prewar period in which real factors and financial factors other than central bank actions played a key role. See Laidler (2003).
} 
past, one can find a number of cases. For example, the Fed's MPS model included a specification of financial institution behavior relating to Regulation Q in the United States, where the ceiling on deposit rates meant that financial institutions were unable to meet the demand for mortgage loans at times of high market interest rates because they were unable to raise the needed funds, and this resulted in fluctuations in the supply of mortgages and in expenditures on housing. In the case of Canada, in the early years before banks were able to raise funds through the wholesale deposit market, the Bank of Canada operated on "credit conditions". The ability of banks to extend loans was influenced by the amount of liquid assets on their balance sheet, which they could use to fund loans. The Bank of Canada's RDX2 model attempted to specify the driving factors behind these credit conditions.

Over the years, with regulatory changes (such as the elimination of regulation Q in the United States) and with the increased sophistication of ways in which banks could raise funds, banks became much less constrained in their ability to extend credit, and macro models focused on the role of interest rates and other factors in determining the demand for credit. But, from time to time, there were episodes in which the normal functioning of financial institutions was disrupted for some reason and the supply of bank credit (not just its demand) became an important factor in private sector expenditures. At the same time, financial markets became increasingly important both in the direct provision of credit to business and in the development of mechanisms (such as the securitization of loans) that facilitated even further the ability of financial institutions to originate the extension of credit to households and businesses. At times, there were also unusual circumstances that affected the functioning of financial markets and influenced consumption and investment expenditures on goods and services.

A listing of some of the episodes in the relatively recent past in which behavior was affected by the supply of funds to households and businesses illustrates the nature of the issue and perhaps the difficulty of finding a simple specification that would cover all the types. In the early 1990s, in the United States, banks became reluctant to provide loans following a period in which they had suffered severe losses that impaired their capital position. Chairman Greenspan referred to this as the "financial headwinds" period and the Fed responded by reducing interest rates to levels well below what would normally have been needed in the circumstances.

A second episode occurred in 1998, when the near failure of LTCM and the Russian debt default caused financial markets to seize up for a short period of time, and prevented borrowers from carrying out their planned funding. For example, there were cases of real estate developers, which 
had been funding their activities by short-term construction loans from banks, who were unable for a short period of time to transfer these obligations into longer-term mortgages, as the typical purchasers of such mortgages were either unwilling or unable to extend such credit at a time of market difficulties.

A third episode relates to the rise and fall of the subprime mortgage market in the United States and the associated developments in derivative markets that were associated with this market. With the spread of subprime mortgages (fueled in part by unusually low interest rates and the apparent ability of lenders to transfer their exposure to others via asset-backed securities), expenditures on housing expanded. At the same time, housing prices rose sharply, and the new financial environment in which households were able to draw on the increased value of their homes via bank loans collateralized by home equity values allowed households to increase their consumption expenditures. As interest rates returned towards neutral levels, the default of many subprime mortgage borrowers, the freezing of liquidity in the asset-backed commercial paper market, and the associated recognition of the necessity to write down the value of many structured financial instruments (well beyond those based on subprime mortgages) have resulted in a situation in which both financial institutions and financial markets are facing serious problems. Many financial institutions have suffered significant losses (in some cases requiring recapitalization), and in such circumstances their ability and willingness to extend loans has been curtailed. And financial markets have been faced with considerable uncertainty about the valuation of certain kinds of financial instruments. As well, there have been lingering liquidity difficulties in certain segments of the market. The difficulties in financial markets and financial institutions showed up in the increased risk spread on issues by private sector borrowers in financial markets and in the tightening of terms and conditions on loans extended by financial institutions, as shown in the Fed's quarterly survey of senior loan officers. As a result, investment projects have had more difficulty being funded than would normally be the case.

What does this imply for economic modeling? Consider first financial accelerators. As far as financial accelerator models are concerned, there can be an endogenous element in which the business cycle leads to increases and decreases of collateral values and hence to the ability to access funding, and an exogenous element in which exogenous shocks to asset values result in changes in the ability of borrowers to obtain financing. While the former can typically be captured to a considerable extent by interest rate movements, it will be important to try to model the latter. One issue that requires careful attention in structural DSGE models is whether financial 
institutions ration credit on the basis of collateral values (such as maximum loan-to-value ratios) or simply tighten terms and conditions on the loans that they are prepared to extend. A second type of financial-real linkage relates to the capital position of financial institutions (most importantly banks) and how it affects the willingness of financial institutions to extend loans. A third type of linkage relates to whether financial markets are functioning normally or are facing either liquidity difficulties or problems in evaluating risks. All the episodes that were listed above and the economic behavior patterns underlying them raise the question of whether financial-real linkages should be part of the central macro model or should be modeled via satellite models. Should they feed into the forecast in normal circumstances or only in unusual episodes? And, if the latter, can they be treated as a form of regime shift?

In this paper, we attempt to integrate financial-real linkages into the type of model described earlier in this paper. ${ }^{10}$ There a number of advantages to using a small model in trying to understand and model the role of the linkages for macro economic behavior. First of all, the insights that have been developed in more complex DSGE and other models can be added to a well-understood macro model to see whether they aid in the explanation of macroeconomic developments. Second, different measures can be used to see which type of proxy is most helpful in capturing the linkages. Third, the small size of the model allows for experimentation of various types. For example, should a proxy for financial-real linkages be introduced as simply an extra variable in the model that functions continuously or should it only be allowed to affect behavior when it reaches critical threshold levels of the sort that were seen in the episodes discussed above? Fourth, by allowing for persistence in real and financial shocks and in their effects on the real economy, judgmental near-term forecasts can play an important role in model-based, medium-term projections through their setting of the initial conditions. Fifth, in a future extension of this work, we plan to develop multicountry models with financial-real linkages, to see whether their cross-border financial effects have played an important role in transmitting the business cycle internationally.

\footnotetext{
${ }^{10}$ See Lown, Morgan, and Rohatgi (2000), Lown and Morgan (2002), Lown and Morgan (2006), Swiston (2008), and Bayoumi and Melander (2008) for earlier attempts to assess the effects of financial-real linkages.
} 


\section{B. Model Specification}

In this version of the model, we make two types of changes to the earlier model. First, we extend the model to include financial-real linkages. Second, we introduce cross correlations into the model.

\section{B.1 Financial-real linkages}

The model with financial-real linkages adds a block of equations with respect to the financial variable BLT, which is an unweighted average of the responses to four questions with respect to tightening terms and conditions in the Federal Reserve Board's quarterly Senior Loan Officer Opinion Survey on Bank Lending Practices. The model also makes the output gap a function of BLT.

More precisely, for each of four questions on bank credit standards on loan applications, ${ }^{11}$ net tightening in BLT is equal to the sum of the percentage of banks responding "tightened considerably" and "tightened somewhat" less the sum of the percentage of banks responding "eased somewhat" and "eased considerably". These net tightening variables are each weighted by one quarter to give the overall BLT variable. It is worth noting that the net tightening responses from the survey outweigh the net easing responses on average over the sample period, indicating a bias of about $5 \%$ in the variable. See figure 4 for a comparison of the output gap from the model without BLT with the results of a simple regression of that output gap on BLT five quarters earlier.

In equation 12, BLT is a function of $\overline{B L T}$, the equilibrium level of BLT, which itself is a random walk (equation 13).

$$
\begin{gathered}
B L T_{t}=\overline{B L T}_{t}-\kappa y_{t+4}+\varepsilon_{t}^{B L T} \\
\overline{B L T}=\overline{B L T}_{t-1}+\varepsilon_{t}^{\overline{B L T}}
\end{gathered}
$$

As shown in equation 12, banks are assumed to tighten or ease their lending practices in a way that depends in part on their view of the expected behavior of the economy 4 quarters ahead. That is, if the output gap is assumed to be positive (a strong economy), there will be a tendency to ease

\footnotetext{
${ }^{11}$ Question 1a on C\&I loans or credit lines to large and middle-market firms, question $1 \mathrm{~b}$ on C\&I loans or credit lines to small firms, question 8 on commercial real estate loans, and question 10 on mortgage loans to purchase homes.
} 
lending conditions, while if it is assumed to be negative (a weak economy), there will be a tendency to tighten lending conditions.

In equation 14, the output gap is explained by the same variables as in equation 8 (a lead and lag of the output gap and the real interest rate gap), as well as by $\eta$, a distributed lag of $\varepsilon^{B L T}$. Thus, if lending conditions are tighter than might have been anticipated on the basis of banks' expectations of future economic behavior (positive $\varepsilon^{B L T}$ ), the effect will be a lower output gap and a weaker economy.

$$
\begin{gathered}
y_{t}=\beta_{1} y_{t-1}+\beta_{2} y_{t+1}-\beta_{3} \operatorname{rrgap}_{t-1}-\theta \eta_{t}+\varepsilon_{t}^{y} \\
\eta_{t}=0.04 \varepsilon_{t-1}^{B L T}+0.08 \varepsilon_{t-2}^{B L T}+0.12 \varepsilon_{t-3}^{B L T}+0.16 \varepsilon_{t-4}^{B L T}+0.20 \varepsilon_{t-5}^{B L T}+0.16 \varepsilon_{t-6}^{B L T}+0.12 \varepsilon_{t-7}^{B L T}+0.08 \varepsilon_{t-8}^{B L T}+0.04 \varepsilon_{t-9}^{B L T}
\end{gathered}
$$

The values of the coefficients imposed in equation 15 are intended to reflect a pattern in which an increase of $\varepsilon^{B L T}$ (a tightening of the credit standards variable) is expected to negatively affect spending by firms and households in a hump-shaped fashion, with an initial buildup and then a gradual rundown of the effects.

There are two ways of thinking about the way that the $\varepsilon^{B L T}$ variable functions in the model. In the first, this proxy variable for financial tightening can be thought of as capturing the exogenous element in bank lending that has the potential to set in motion a weakening or strengthening economic situation. That is, those responsible for bank lending look forward to economic conditions about a year in the future and tighten or loosen in part on the basis of their expectations. If their actions are typical for the stage of the cycle, the interest rate variable itself may pick up the normal tightening and easing of terms and conditions on bank lending, and BLT would play little role in driving future economic developments. If, on the other hand, their actions are greater or less than is typical in light of the expected economic situation, this could have a direct effect on the ability of borrowers to access funds and to make expenditures. A second interpretation puts less emphasis on the direct effects on expenditures of the tightening or easing of planning conditions. Rather, from this perspective, one can consider the $\varepsilon^{B L T}$ variable as reflecting the views of experts on the lending side of the economy with respect to future economic and financial conditions and thereby functioning as a very useful leading indicator of economic developments.

There are a number of issues surrounding this variable. First, in the interpretation that focuses on 
the exogenous part of this variable, it is assumed that the part of financial-real linkages that propagates other typical shocks to the system is captured by the interest rate. This is not an unreasonable assumption, since the endogenous part of the financial accelerator mechanism intensifies the effects on the economy of other shocks and, in a macro sense, could be thought of as simply increasing the coefficient on the interest rate variable. Second, there could be an asymmetry between positive and negative shocks to BLT. While financial conditions that are tighter than typical will have the effect of preventing liquidity-constrained households and businesses from achieving their desired expenditures, beyond a certain point the easing of financial conditions may be less powerful in leading to increased spending. That is, once there is sufficient collateral to satisfy lenders of the safety of their loans, a further increase in the value of the collateral may not affect their behavior. Third, it is possible that small changes in financial conditions will have relatively minor effects, and only changes beyond a certain critical threshold will have the capacity to bring about economically significant changes. We tested this by setting all values of the BLT variable that were less than 15 in absolute value to zero. The only noteworthy change in the results is that $\theta$, the effect of the $\eta$ variable on the output gap, declines appreciably, the reverse of our expectations. Fourth, given the complexity of the financial-real linkages in the economy, BLT may not be able to capture all types of linkages, and other variables (such as risky spreads) should be introduced into the equation to try to pick up some of the other effects.

\section{B.2 Cross correlations of disturbances}

This version of the model also contains two types of cross correlations of error terms. The first involves a positive correlation between $\varepsilon^{g^{\bar{Y}}}$ and $\varepsilon^{y}$. The basic idea is that a positive shock to potential output growth that is expected to persist for a considerable period of time will be associated with an increase in expected permanent income, which will raise spending by households even before the level of potential output increases. Similarly, businesses will be motivated to increase their investment spending on the basis of the expected faster growth in potential output. Thus, aggregate demand and actual output will rise before potential output and there will be an increase in the output gap as a result of the shock to the growth rate of potential output. The second cross correlation involves a positive correlation between $\varepsilon^{\bar{Y}}$ and $\varepsilon^{\pi}$. This implements in the model the notion that a positive supply shock to potential output puts downward pressure on costs and prices and results in a positive correlation between these two 
disturbances (since the error term in the inflation equation enters with a negative sign). This correlation structure is used to roughly mimic the IRFs that have been estimated from DSGE models of the U.S. economy and provides an example of how the dynamics of smaller semi-structural models can embody some of the insights from our deeper structural models - see Juillard and others $(2007,2008)$.

\section{Results}

The addition of the financial variable to the model improves its functioning markedly. Tables 4 and 5 show the priors and posteriors for the model with the financial variable and can be compared with those shown in tables 1 and 2 from the base model without the financial variable. The major difference is in the output gap equation. Adding the financial variable significantly reduces the weights on both the lagged output gap variable and the lead output gap variable and slightly increases the weight on the real interest rate variable. It also significantly increases the coefficient on the lagged dependent variable in the unemployment gap equation. The changes in the standard deviations of the structural shocks resulting from the addition of the financial variable to the model are relatively minor.

Table 6 shows the results of the estimation of the cross correlation of structural shocks in the model with the financial variable. There is a moderately sizable correlation between the shock to the growth of potential output and the shock to the output gap, and a relatively small correlation between the shock to the level of potential output and the shock to the rate of inflation.

As far as the impulse response functions are concerned (figures 5 to 10), the model shows reasonable and expected patterns. A shock to the disturbance term in the inflation equation (a downward shock to inflation) leads to a decline in the nominal and real policy interest rate and thereby to an increase in the output gap and a decline in the unemployment gap. The effects are accentuated by the easing of the terms and conditions on bank lending. A shock to the disturbance in the output gap equation leads to an increase in the output gap, a decline in the unemployment gap and to an increase in inflation and in the policy interest rate. A shock to the disturbance term in the equation for the short-term interest rate has the expected effect of reducing output, increasing unemployment and putting downward pressure on the rate of inflation. The response of output to a shock in the BLT equation (a tightening in bank lending) is sizable and reflects the hump-shaped distributed lag in the output gap equation imposed in the $\eta$ equation. It brings in its 
wake a rise in unemployment, and a decline in inflation and in the policy interest rate. The last two impulse response functions illustrate that a shock to the growth rate of potential output has much larger effects than a shock to the level of potential output. As discussed earlier, the shock to the growth rate of potential output leads to an increase in demand, a rise in the output gap (operating through the cross correlation between the error term in the potential growth equation and that in the output gap equation), with a subsequent increase an inflation and policy interest rates. The shock to the level of potential output has little effect on the output gap or interest rates, but it does lead to some decline in inflation, probably because of the cross correlation between the error term in the equation for the level of potential output and that in the inflation equation. Interestingly, a shock to the equilibrium real interest rate (not shown) leads to a corresponding change to the nominal interest rate and very little effect on the other variables in the system.

Tables 3 and 7 show the RMSEs over the sample period from the base model without financial variables and the model with financial variables. The most striking results in these tables is the sharp decline in the RMSE on the output gap at all horizons and on the 4-quarter rate of inflation in the four-quarter and eight-quarter ahead forecasts in going from the base model without the financial variable to the model with the financial variable. On the other hand, there is some deterioration in the shorter-term NAIRU forecasts.

Table 8 reports the unconditional theoretical moments and the contribution of the five most significant shocks based on the estimated modes. ${ }^{12}$ The estimated model produces plausible estimates of the first and second unconditional moments. The table also shows clearly the important role of the BLT variable in driving variation in output, unemployment, inflation, and the fed funds rate. Unlike conventional macro models, where the own shocks of each equation explain a substantial proportion of the variation of each variable, this model ascribes a much more important role to innovations in the BLT variable, accounting for about 70 percent of the variation in the output and unemployment gaps and 40 percent of the variation in year-on-year GDP growth and inflation. Interestingly, the shocks to the fed funds rate make a very small contribution to the variability in the fed funds rate, showing that most variation in interest rates over the sample has been a result of the Federal Reserve reacting to information instead of being a source of shocks as it was in earlier periods.

\footnotetext{
${ }^{12}$ By significant we mean the shocks that account for at least 10 percent of the variation in the stationary variables of the model.
} 
Figures 11 through 22 present 8-quarter ahead dynamic forecasts over the second half of the sample period based on the models with and without BLT. While the model that includes the financial variable is able to track the unemployment gap and the output gap moderately well, it has more difficulty in tracking the dynamics of output growth and inflation. Interestingly, both models show a tendency for interest rates to rise in 2003, more than a year before the Fed took action to raise rates. The inability to track the policy interest rate during this period is not surprising, since there is nothing in the model to capture the notion of concern about price deflation and the zero lower bound for nominal interest rates.

\section{Some Extensions}

\section{D.1 Comparison of results from long sample and short sample for model with financial variable}

There may have been a change in the structure of the economy in which the financial-real linkages began to play a more important and continuing role in real economic developments in this decade (following the anchoring of inflation expectations) compared to earlier decades. We therefore confronted the model with the financial variable with the data for the short period (2001 to 2007) and compared the results to those for the long period that we have used throughout this paper. While the results are similar by and large, there are a number of interesting differences. In the equation for the output gap, the coefficient on the lagged gap is appreciably larger for the small sample. More significantly, there is a much larger coefficient on the financial variable in the output gap equation in the short sample, indicating that the financial variable has played a stronger role in influencing the output gap in this decade than it did earlier. Another striking change is that the RMSE for the 4-quarter, 8-quarter and 12-quarter ahead forecasts of one-quarter and four-quarter growth in output are much lower for the shorter sample period than for the longer sample period. This is consistent with the much smoother growth of output in the current decade, as is also shown by the sharp decline in the standard deviation of the structural shock in the potential output growth equation in moving from the longer sample period to the shorter sample period. 


\section{D.2 Core CPI}

The replacement of total CPI inflation by core CPI inflation did not make a great deal of difference to most of the results, although there were a few exceptions. The most striking exception, and one that was entirely consistent with our expectations, was the very sharp decline in the posterior estimate of the standard deviation of the structural shock in the inflation equation. It fell from about 1.35 to 0.4 in the base model and from about 1.25 to 0.4 in the model with the financial variable. Two other interesting results were that the inflation equation was more backward looking with core inflation than it was with headline inflation and that the reaction function showed a substantially stronger response of the policy interest rate to an increase in core inflation than to headline inflation. The explanation for the former result relates to a reluctance on the part of the public to treat a movement in headline inflation as a good indicator of future inflation, because of their awareness of the sensitivity of headline inflation to temporary shocks. In a similar way, the latter result relates to the considerably greater concern of the monetary authorities about a movement of core inflation than of headline inflation, both because of the greater likelihood that movements in headline inflation are temporary and reversible, and also because such movements are less likely to affect expectations of future inflation than those of core inflation.

\section{Concluding Remarks}

This is the first of a series of papers that are being written as part of a larger project to estimate a small quarterly Global Projection Model (GPM). The GPM project is designed to improve the toolkit to which economists have access for studying both own-country and cross-country macro linkages and financial-real linkages. In this paper, we estimated a small quarterly projection model of the U.S. economy in which the endogenous variables were output, unemployment, inflation and the federal funds rate. The model was estimated with Bayesian techniques, which provide a very efficient way of imposing restrictions to produce both plausible dynamics and sensible forecasting properties. An important advantage of these techniques is that they allow researchers to estimate models with flexible stochastic processes, which can provide timely and more efficient model-consistent measures of potential output and other latent variables in the system. After developing a benchmark model without financial-real linkages, we introduced such 
linkages into the model, along with cross correlations of disturbances, and compared the results with and without linkages and cross correlations.

Two extensions are in progress. First, we have developed a series of 2-country open-economy versions of the model to estimate the spillover effects of tightening credit conditions in the U.S. on other countries and regions of the world. Second, the basic model will be extended to include other financial variables including alternative measures of risky spreads and asset prices. After these two initial steps are completed the next phase will be to build a multicountry version of the model so that we can assess if spillovers across countries are generated more through financial linkages than through conventional trade linkages. 


\section{References:}

Argov, E., N. Epstein, P. Karam, D. Laxton, and D. Rose, 2007, “Endogenous Monetary Policy Credibility in a Small Macro Model of Israel,’ IMF Working Paper 07/207 (August), available at www.imf.org.

Bayoumi, T. and A. Swiston, 2007, "Foreign Entanglements: Estimating the Source and Size of Spillovers Across Industrial Countries,” IMF Working Paper No. 07/182 (July), available at www.imf.org.

Bayoumi, T. and O. Melander, 2008, “Credit Matters: Empirical Evidence on U.S.

Macro-Financial Linkages," IMF Working Paper No. 08/169 (July), available at www.imf.org.

Berg, A., P. Karam, and D. Laxton, 2006a, “A Practical Model-Based Approach to Monetary Policy Analysis-Overview," IMF Working Paper 06/080 (April), available at www.imf.org.

Berg, A., P. Karam, and D. Laxton, 2006b, "Practical Model-Based Monetary Policy Analysis-A How-to Guide," IMF Working Paper 06/081 (April), available at www.imf.org.

Bernanke, B. S., and M. Gertler, 1995, "Inside the Black Box: The Credit Channel of Monetary Policy Transmission,” Journal of Economic Perspectives (Fall), pp. 27-48.

Botman, D., P. Karam, D. Laxton, and D. Rose, 2007, "DSGE Modeling at the Fund: Applications and Further Developments," IMF Working Paper 07/200 (August), available at www.imf.org.

Coats, W., D. Laxton, and D. Rose, 2003, “The Czech National Bank's Forecasting and Policy Analysis System,” (Prague, Czech Republic: Czech National Bank).

Epstein, N., D. Laxton, P. Karam, and D. Rose, 2006, “A Simple Forecasting and Policy Analysis System for Israel: Structure and Applications," in Israel: Selected Issues, IMF Country Report No. 06/121 (March), available at www.imf.org.

Juillard, M., O. Kamenik, M. Kumhof, and D. Laxton, 2007, "Measures of Potential Output from An Estimated DSGE Model of the United States," paper presented at a workshop on Issues in Measuring Potential Output (Ankara Turkey).

Juillard, M., O. Kamenik, D. Laxton, and M. Kumhof, 2008, “Optimal Price Setting and Inflation Inertia in a Rational Expectations Model," (forthcoming) Journal of Economic Dynamics and Control. 
Laidler D., 2003, “The Price Level, Relative Prices and Economic Stability: Aspects of the Interwar Debate,’ BIS Working Papers No. 136 (September), available at www.bis.org.

Lown, C., D. Morgan, and S. Rohatgi, 2000, "Listening to Loan Officers: The Impact of Commercial Credit Standards on Lending and Output," Federal Reserve Bank of New York Economic Policy Review (July), pp. 1-16.

Lown, C. and D. Morgan, 2002, "Credit Effects in the Monetary Mechanism," Federal Reserve Bank of New York Economic Policy Review (May), pp. 217-35.

— 2006, "The Credit Cycle and the Business Cycle: New Findings Using the Loan Officer Opinion Survey,' Journal of Money, Credit, and Banking, Vol. 38 (September), pp. 1575-97.

Meyer L., 2000, “The Economic Outlook and the Challenges Facing Monetary Policy,” Remarks at the Century Club Breakfast Series (Washington University, St. Louis: Missouri), available at www.federalreserve.gov.

Orphanides, A., 2003, "Historical Monetary Policy Analysis and The Taylor Rule," Journal of Monetary Economics (July), pp. 983-1022.

Swiston, A., 2008, "A U.S. Financial Conditions Index: Putting Credit Where Credit is Due," IMF Working Paper No. 08/161 (June), available at www.imf.org. 


\title{
Appendix: Data Definitions
}

\author{
United States

GDP U.S.: $\quad$ Gross Domestic Product (SAAR, Bil.Chn.2000.Dollars) \\ Interest rates $\quad$ Federal Open Market Committee: Fed Funds Target Rate (percent) (period average) \\ CPI U.S.: $\quad$ Consumer Price Index (SA, 1982-84=100) \\ Core CPI U.S.: CPI-U: All Items Less Food and Energy (SA, 1982-84=100) \\ Unemployment U.S.: Civilian Unemployment Rate (SA, percent) \\ Bank lending \\ tightening (BLT) Average of: \\ FRB Sr Officers Survey: Banks Tightening C.I Loans to Large Firms (percent) \\ FRB Sr Officers Survey: Banks Tightening C.I Loans to Small Firms (percent) \\ FRB Sr Loan Off Survey: Tightening Standards for Commercial Real Estate (percent) \\ FRB Sr Loan Survey: Res Mortgages: Net Share, Banks Tightening (Haver Est, percent)
}




\section{Figure 1: US Historical data}

United States

Real GDP Growth (In percent; solid=year-on-year, dashed=quarter-on-quarter)
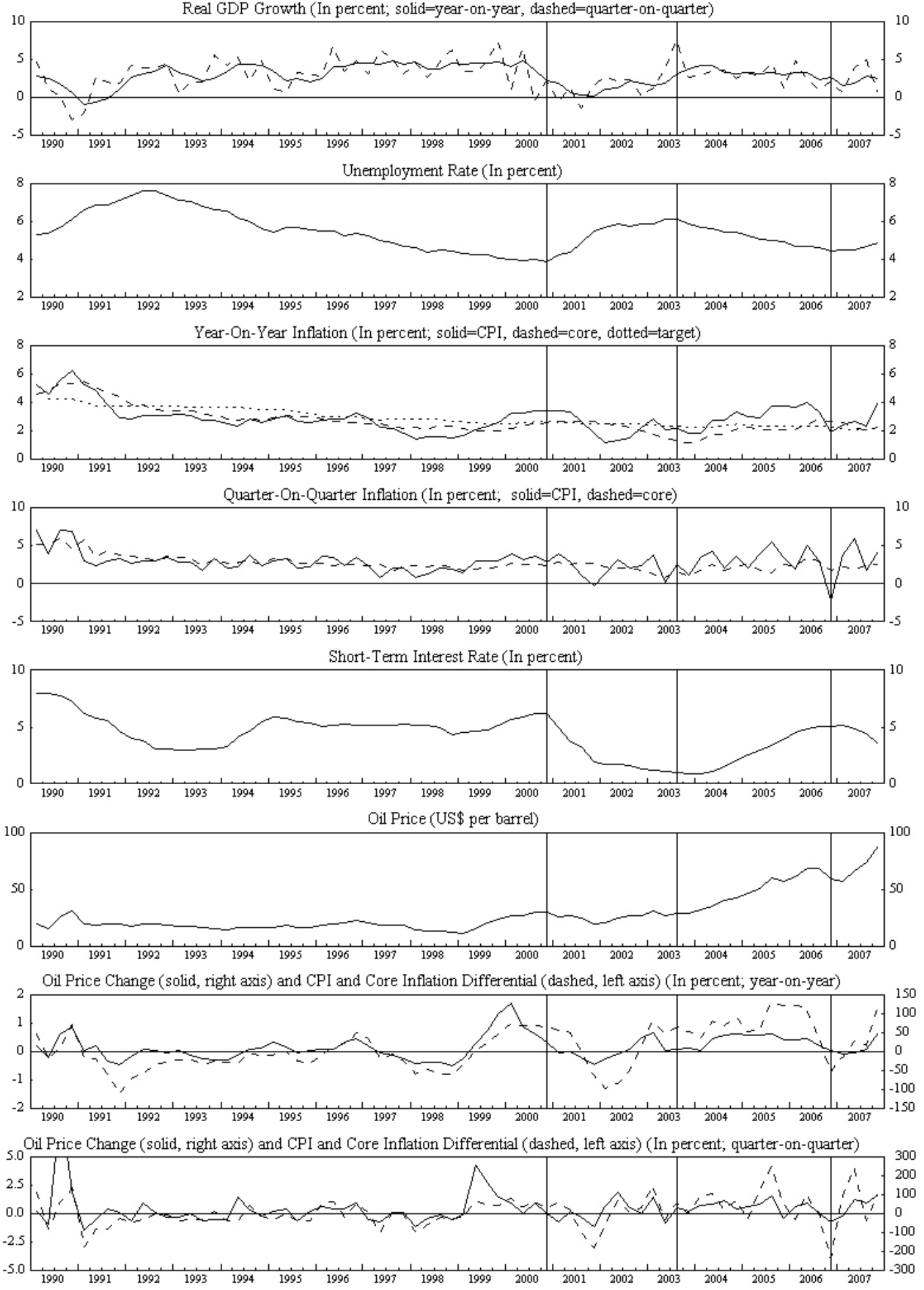
Table 1: Results From Posterior Maximization (parameters) Base Case Model

\begin{tabular}{l|lcccc}
\hline \hline & & & & & \\
& Prior distribution & Prior mean & Prior s.d. & Posterior mode & s.d. \\
\hline$\alpha_{u s 1}$ & beta & 0.800 & 0.1000 & 0.7453 & 0.0581 \\
$\alpha_{u s 2}$ & gamm & 0.300 & 0.2000 & 0.1711 & 0.0310 \\
$\alpha_{u s 3}$ & beta & 0.500 & 0.2000 & 0.3339 & 0.1931 \\
$g_{u s}^{\bar{Y} s}$ & norm & 2.500 & 0.2500 & 2.6016 & 0.2360 \\
$\overline{r r}_{u s}$ & norm & 2.000 & 0.2000 & 1.8221 & 0.1729 \\
$\rho_{u s}$ & beta & 0.900 & 0.0500 & 0.9239 & 0.0462 \\
$\tau_{u s}$ & beta & 0.100 & 0.0500 & 0.0768 & 0.0389 \\
$\beta_{u s 1}$ & gamm & 0.750 & 0.1000 & 0.8523 & 0.0817 \\
$\beta_{u s 2}$ & beta & 0.150 & 0.1000 & 0.1674 & 0.0971 \\
$\beta_{u s 3}$ & gamm & 0.200 & 0.0500 & 0.1270 & 0.0290 \\
$\lambda_{u s 1}$ & beta & 0.500 & 0.1000 & 0.7272 & 0.0613 \\
$\lambda_{u s 2}$ & gamm & 0.250 & 0.0500 & 0.1937 & 0.0382 \\
$\gamma_{u s 1}$ & beta & 0.500 & 0.0500 & 0.7087 & 0.0365 \\
$\gamma_{u s 2}$ & gamm & 1.500 & 0.3000 & 1.2679 & 0.2271 \\
$\gamma_{u s 4}$ & gamm & 0.200 & 0.0500 & 0.2192 & 0.0563 \\
\hline \hline
\end{tabular}


Table 2: Results From Posterior Maximization (standard deviation of structural shocks) Base Case Model

\begin{tabular}{|c|c|c|c|c|c|}
\hline & Prior distribution & Prior mean & Prior s.d. & Posterior mode & s.d. \\
\hline$\varepsilon_{u s}^{u}$ & invg & 0.200 & Inf & 0.0943 & 0.0146 \\
\hline$\varepsilon_{u s}^{\bar{U}}$ & invg & 0.100 & Inf & 0.0466 & 0.0193 \\
\hline$\varepsilon_{u s}^{g \bar{U}}$ & invg & 0.100 & Inf & 0.0455 & 0.0166 \\
\hline$\varepsilon_{u s}^{y}$ & invg & 0.250 & Inf & 0.3567 & 0.0585 \\
\hline$\varepsilon_{u \underline{s}}^{\bar{Y}}$ & invg & 0.100 & Inf & 0.0483 & 0.0218 \\
\hline$\varepsilon_{u s}^{g^{Y}}$ & invg & 0.100 & Inf & 0.3486 & 0.1326 \\
\hline$\varepsilon_{u s}^{\pi}$ & invg & 0.700 & Inf & 1.3598 & 0.1440 \\
\hline$\varepsilon_{u s}^{r s}$ & invg & 0.700 & Inf & 0.4643 & 0.0605 \\
\hline$\varepsilon_{u s}^{\overline{r r}}$ & invg & 0.200 & $\operatorname{Inf}$ & 0.0934 & 0.0393 \\
\hline
\end{tabular}


Figure 2: Unemployment and Model-Consistent NAIRU

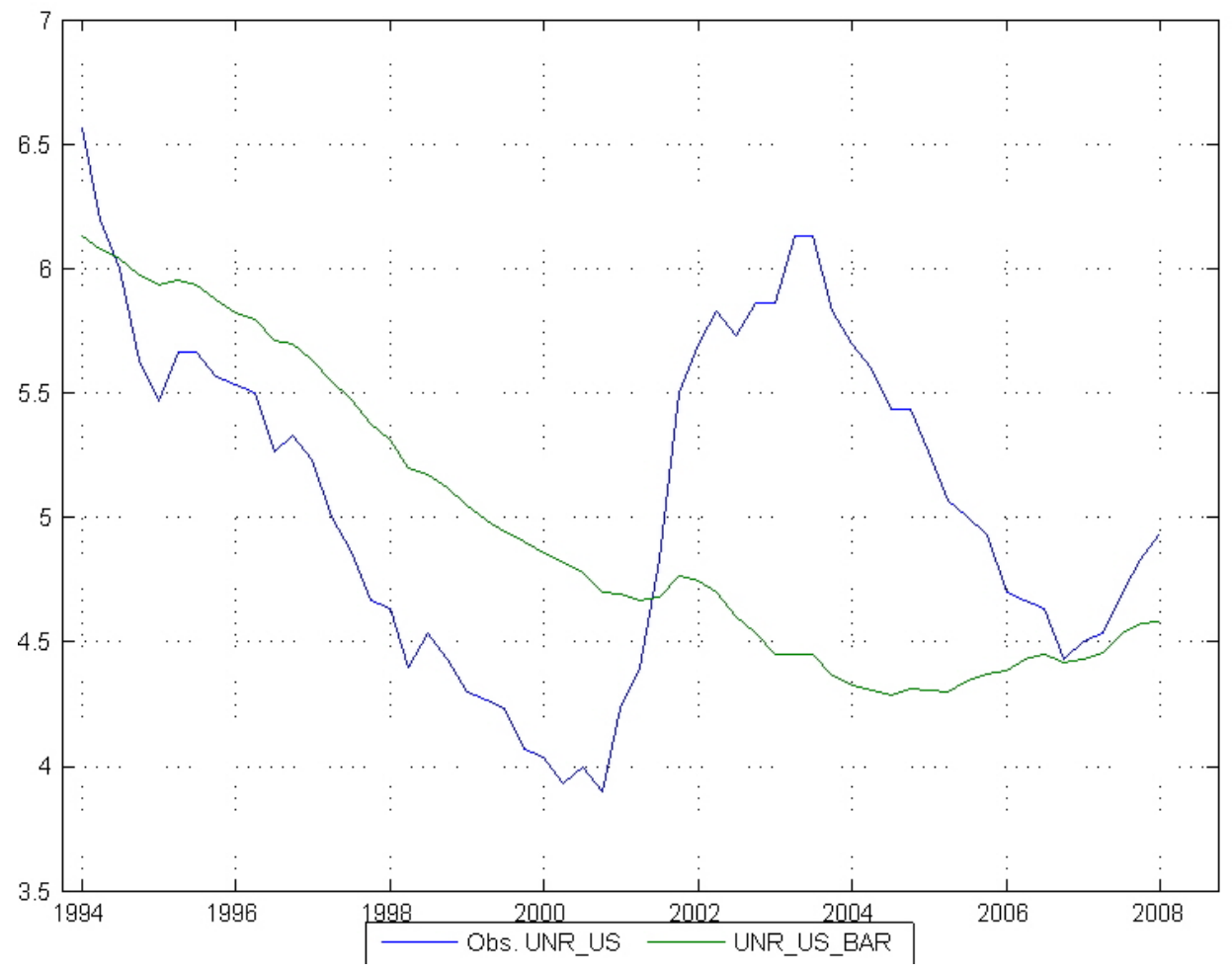


Figure 3: GDP and Model-Consistent Potential GDP

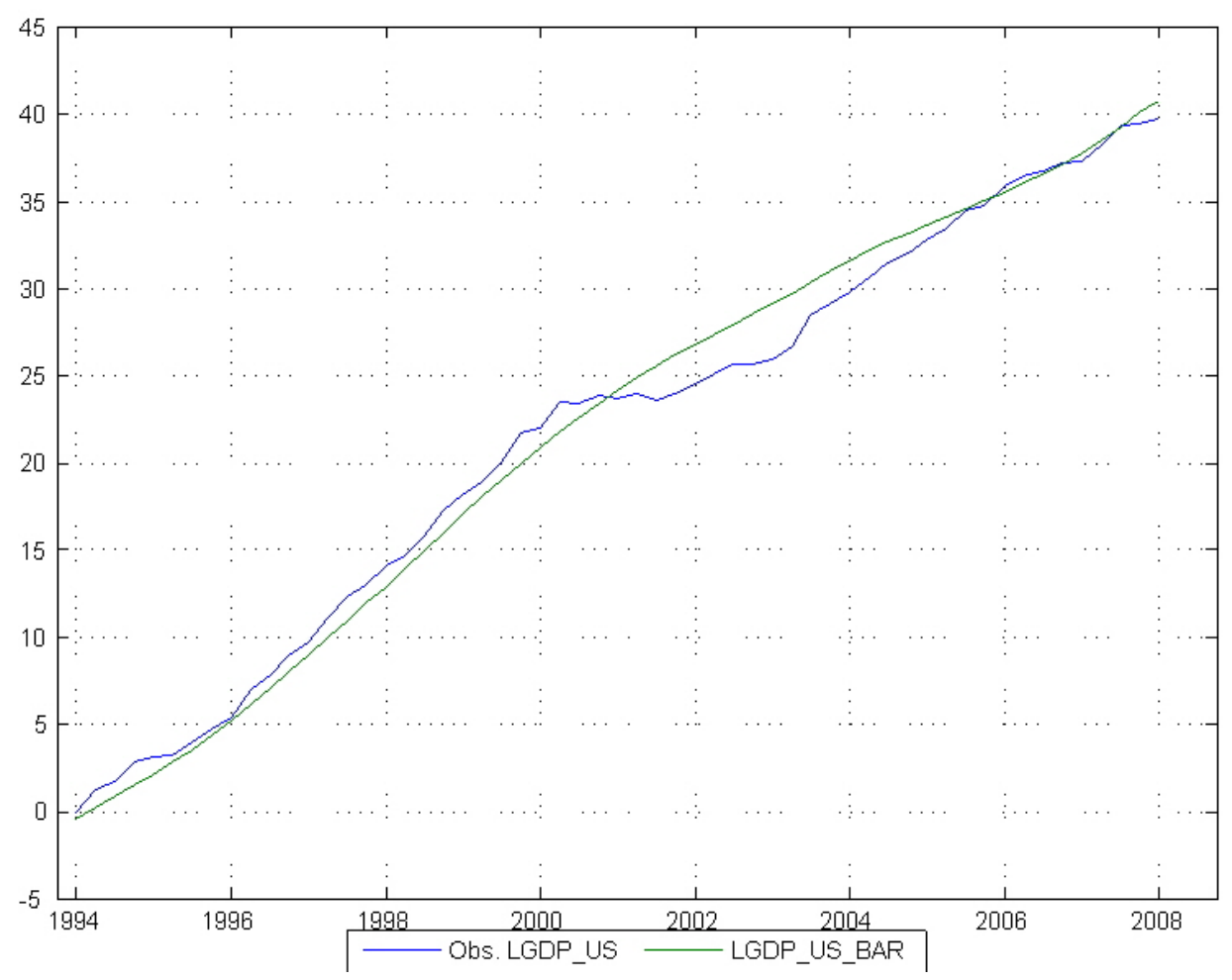


Table 3: Base Case Root Mean Squared Errors

\begin{tabular}{l|lccc}
\hline \hline & 1 Q Ahead & 4 Q Ahead & 8 Q Ahead & 12 Q Ahead \\
\hline & 0.63 & 0.9 & 1.3 & 1.4 \\
$y_{u s}$ & 0.36 & 1 & 0.89 & 0.78 \\
$\pi 4_{u s}$ & 0.43 & 1 & 1.4 & 1.8 \\
$r s_{u s}$ & 0.15 & 0.39 & 0.74 & 1 \\
$U_{u s}$ & 0.2 & 0.32 & 0.48 & 0.63 \\
$\bar{U}_{u s}$ & 1.9 & 2 & 2.1 & 2 \\
$4\left(Y_{u s}-Y_{u s,-1}\right)$ & 0.53 & 1.2 & 1.4 & 1.4 \\
$Y_{u s}-Y_{u s,-4}$ & 0.4 & 0.65 & 0.8 & 0.88 \\
$\bar{Y}_{u s}-\bar{Y}_{u s,-4}$ & \multicolumn{4}{l}{} \\
\hline \hline
\end{tabular}


Figure 4:

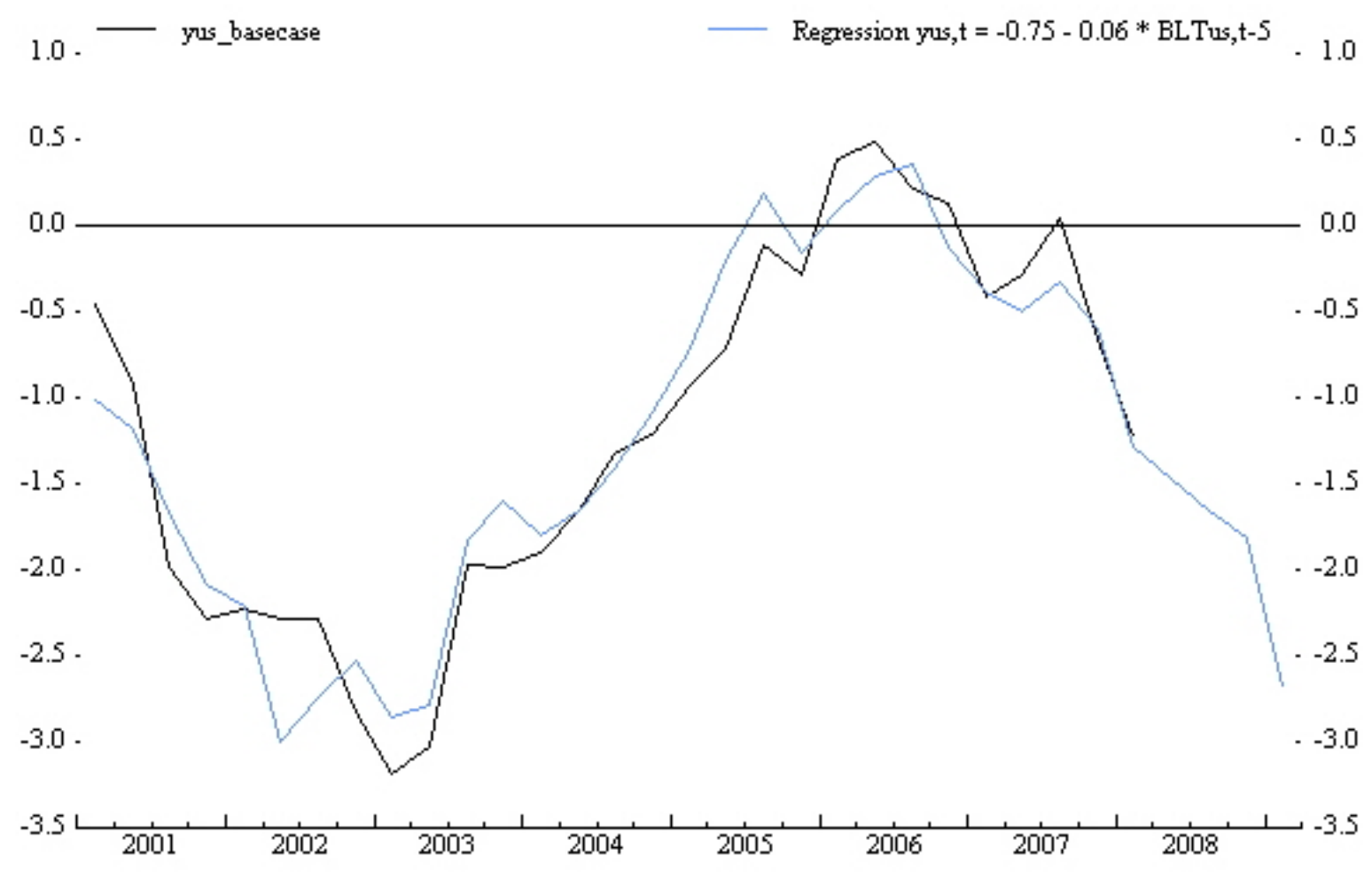


Table 4: Results From Posterior maximization (parameters) BLT Model

\begin{tabular}{l|lcccc}
\hline \hline & & & & & \\
& Prior distribution & Prior mean & Prior s.d. & Posterior mode & s.d. \\
\hline$\alpha_{u s 1}$ & beta & 0.800 & 0.1000 & 0.8710 & 0.0484 \\
$\alpha_{u s 2}$ & gamm & 0.300 & 0.2000 & 0.1688 & 0.0279 \\
$\alpha_{u s 3}$ & beta & 0.500 & 0.2000 & 0.5175 & 0.2724 \\
$g_{u s s} \bar{Y}_{s s}$ & norm & 2.500 & 0.2500 & 2.6227 & 0.2323 \\
$\overline{r r}$ & norm & 2.000 & 0.2000 & 1.8121 & 0.1754 \\
$\rho_{u s}$ & beta & 0.900 & 0.0500 & 0.9240 & 0.0462 \\
$\tau_{u s}$ & beta & 0.100 & 0.0500 & 0.0813 & 0.0373 \\
$\beta_{u s 1}$ & gamm & 0.750 & 0.1000 & 0.6840 & 0.0559 \\
$\beta_{u s 2}$ & beta & 0.150 & 0.1000 & 0.0495 & 0.0525 \\
$\beta_{u s 3}$ & gamm & 0.200 & 0.0500 & 0.1360 & 0.0303 \\
$\lambda_{u s 1}$ & beta & 0.500 & 0.1000 & 0.7091 & 0.0590 \\
$\lambda_{u s 2}$ & gamm & 0.250 & 0.0500 & 0.2224 & 0.0381 \\
$\gamma_{u s 1}$ & beta & 0.500 & 0.0500 & 0.7762 & 0.0254 \\
$\gamma_{u s 2}$ & gamm & 1.500 & 0.3000 & 1.2993 & 0.2399 \\
$\gamma_{u s 4}$ & gamm & 0.200 & 0.0500 & 0.2102 & 0.0546 \\
$\kappa_{u s}$ & gamm & 20.000 & 0.5000 & 19.9943 & 0.4956 \\
$\theta_{u s}$ & gamm & 1.000 & 0.5000 & 1.2824 & 0.5621 \\
\hline \hline
\end{tabular}


Table 5: Results From Posterior Maximization (standard deviation of structural shocks) BLT Model

\begin{tabular}{l|lcccc}
\hline \hline & & & & & \\
& Prior distribution & Prior mean & Prior s.d. & Posterior mode & s.d. \\
\hline$\varepsilon_{u s}^{u}$ & invg & 0.200 & Inf & 0.0989 & 0.0161 \\
$\varepsilon_{u s}^{U}$ & invg & 0.100 & Inf & 0.0473 & 0.0200 \\
$\varepsilon_{u s}^{g^{U}}$ & invg & 0.100 & Inf & 0.0445 & 0.0161 \\
$\varepsilon_{u s}^{y}$ & invg & 0.250 & Inf & 0.3490 & 0.0416 \\
$\varepsilon_{u s}^{\bar{Y}}$ & invg & 0.050 & Inf & 0.0230 & 0.0094 \\
$\varepsilon_{u s}^{g Y}$ & invg & 0.100 & Inf & 0.3319 & 0.0856 \\
$\varepsilon_{u s}^{\pi}$ & invg & 0.700 & Inf & 1.2353 & 0.1189 \\
$\varepsilon_{u s}^{r s}$ & invg & 0.700 & Inf & 0.4712 & 0.0556 \\
$\varepsilon_{u s}^{r r}$ & invg & 0.200 & Inf & 0.0934 & 0.0391 \\
$\varepsilon_{u s}^{B L T}$ & invg & 0.400 & Inf & 0.8082 & 0.3342 \\
$\varepsilon_{u s}^{B L T}$ & invg & 0.200 & Inf & 0.0928 & 0.0384 \\
\hline \hline
\end{tabular}


Table 6: Results from posterior parameters (correlation of structural shocks) BLT Model

\begin{tabular}{l|lcccc}
\hline \hline & Prior distribution & Prior mean & Prior s.d. & Posterior mode & s.d. \\
\hline & & & & & \\
$\varepsilon_{u s}^{y}, \varepsilon_{u s}^{g^{\bar{Y}}}$ & beta & 0.250 & 0.1000 & 0.1944 & 0.0928 \\
$\varepsilon_{u s}^{Y}, \varepsilon_{u s}^{\pi}$ & beta & 0.050 & 0.0200 & 0.0422 & 0.0187 \\
\hline \hline
\end{tabular}


Figure 5: IRF Supply Shock $\left(\varepsilon_{u s}^{\pi}\right)$
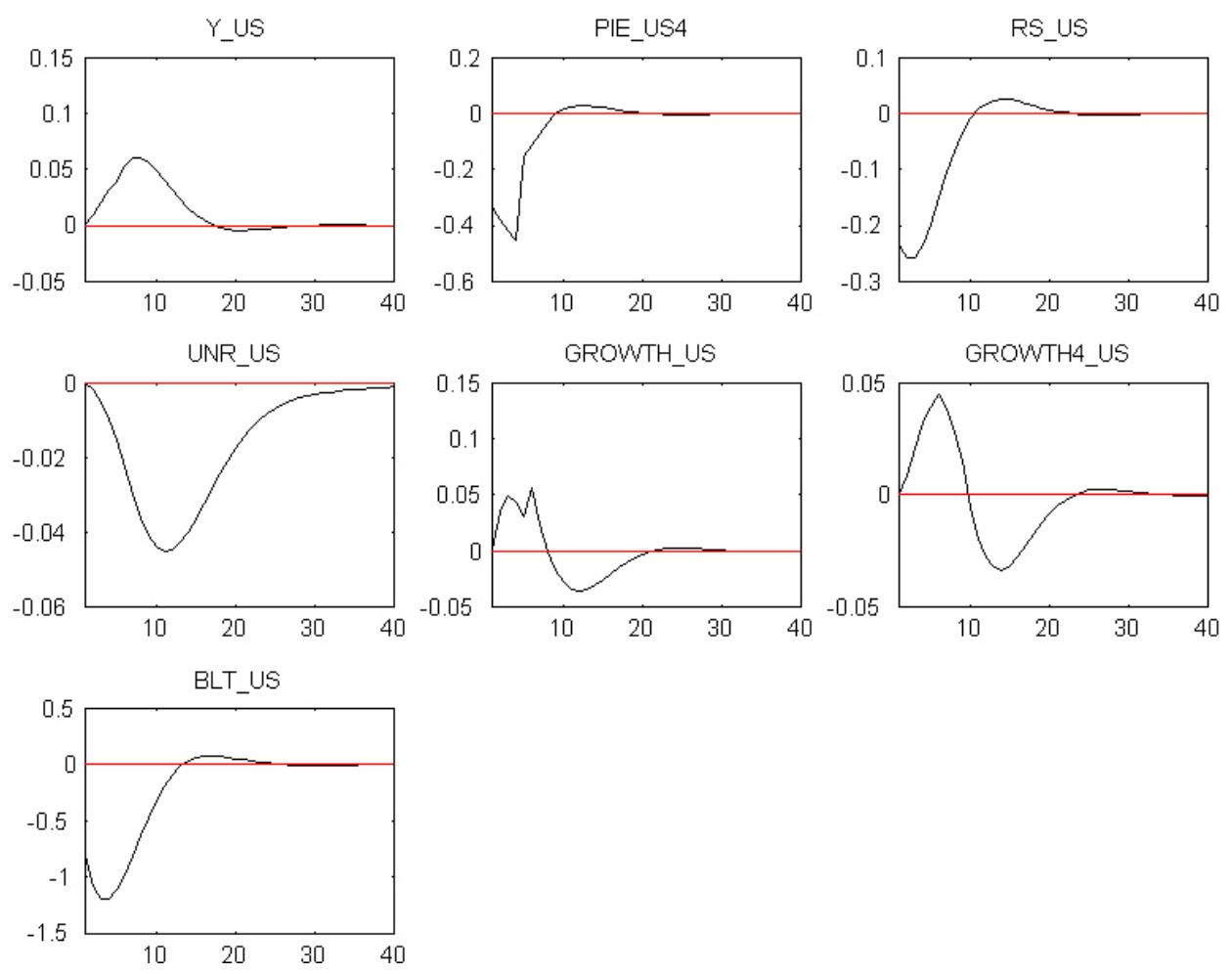
Figure 6: IRF Demand Shock $\left(\varepsilon_{u s}^{y}\right)$
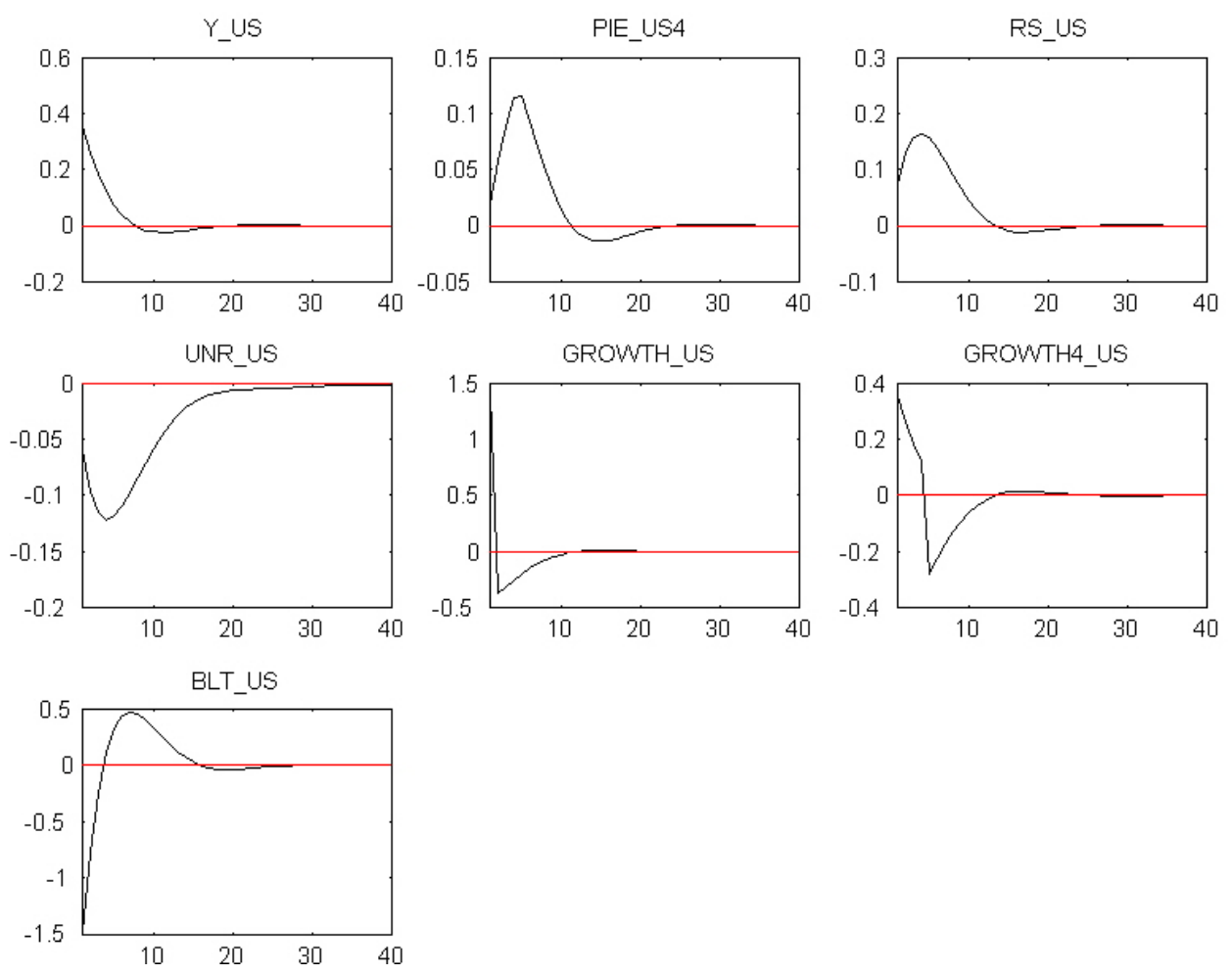
Figure 7: IRF Policy Rate Shock $\left(\varepsilon_{u s}^{r s}\right)$
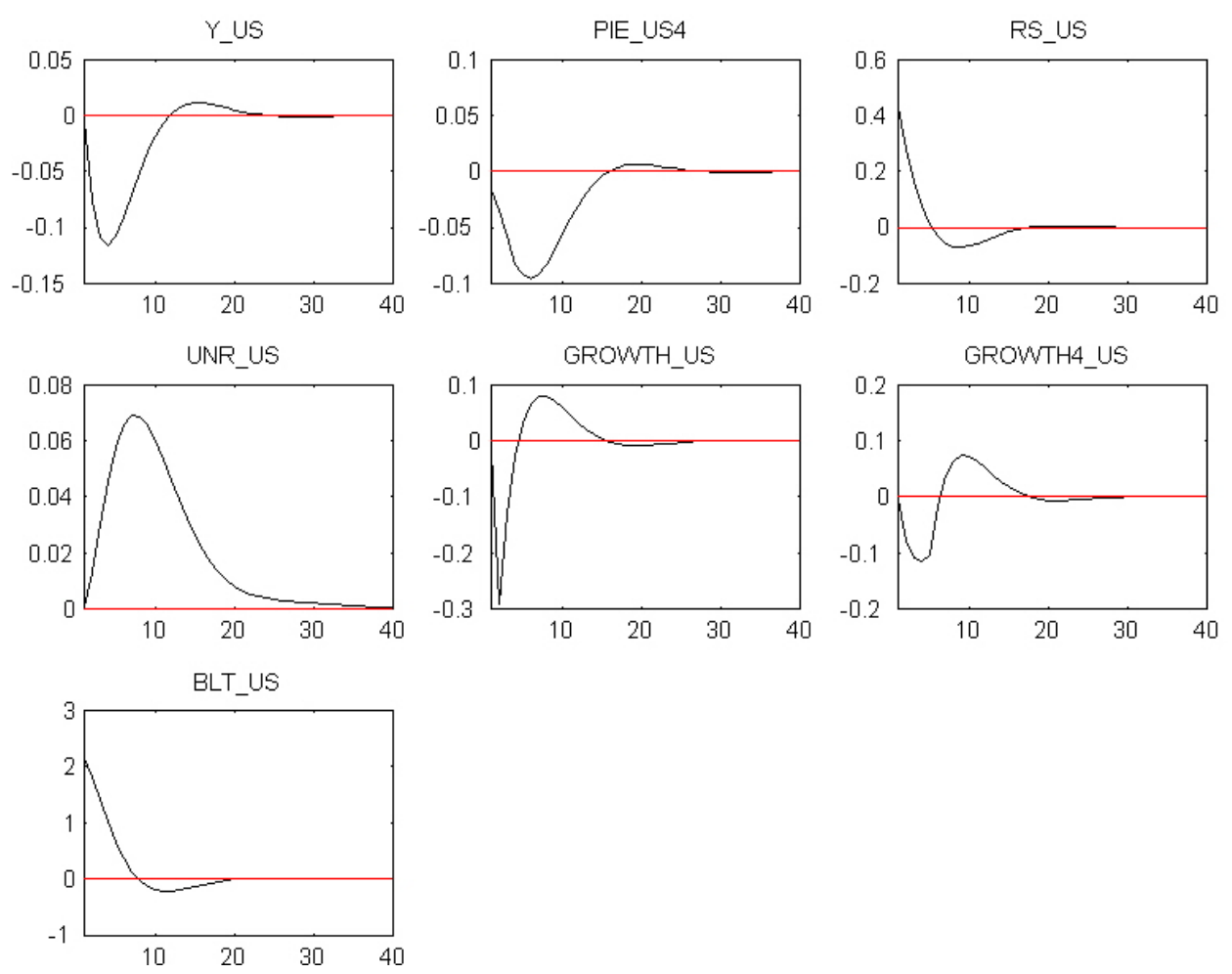
Figure 8: IRF BLT Shock $\left(\varepsilon_{u s}^{B L T}\right)$
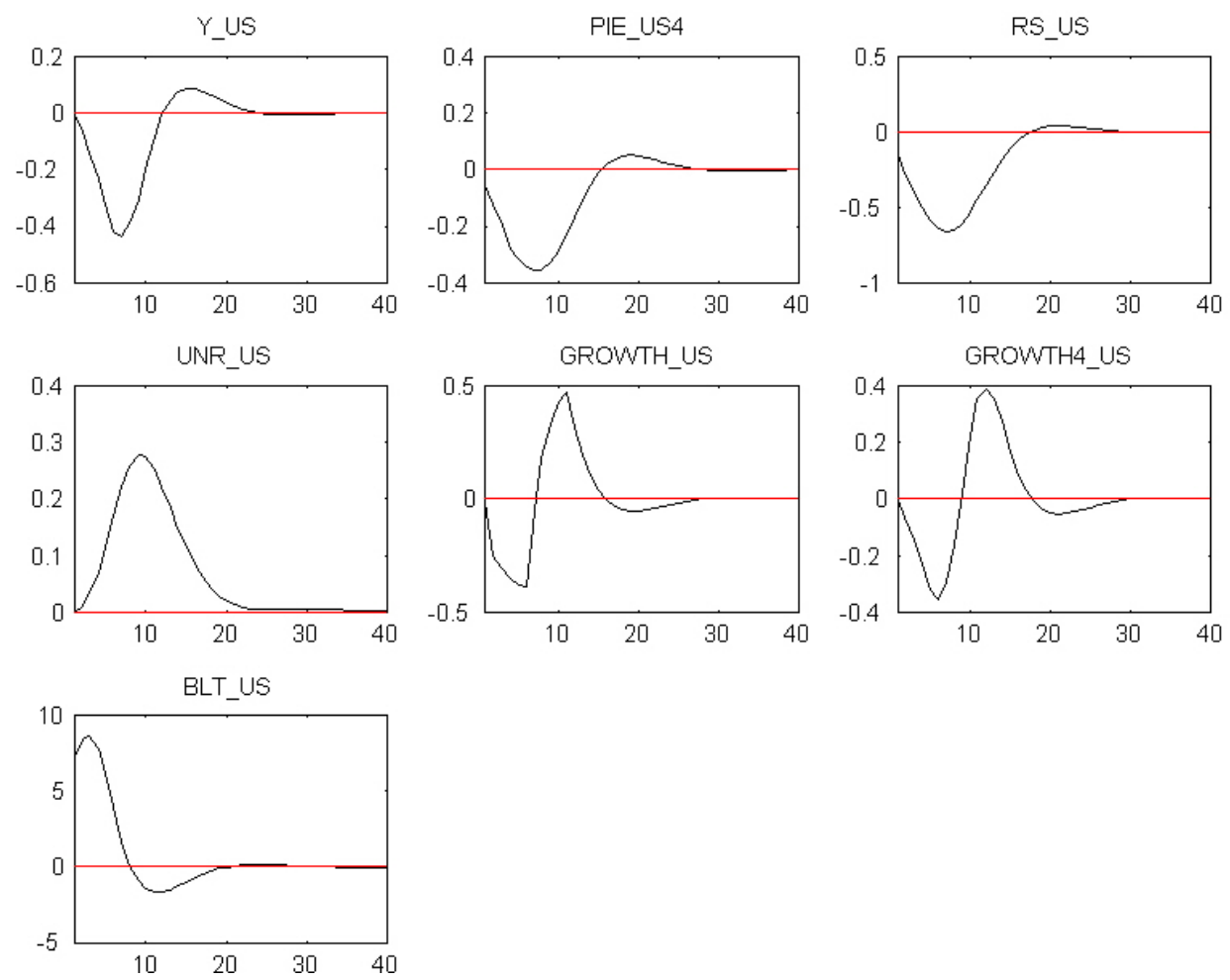
Figure 9: IRF Equilibrium GDP Growth Shock $\left(\varepsilon_{u s}^{\overline{Y^{\bar{Y}}}}\right)$
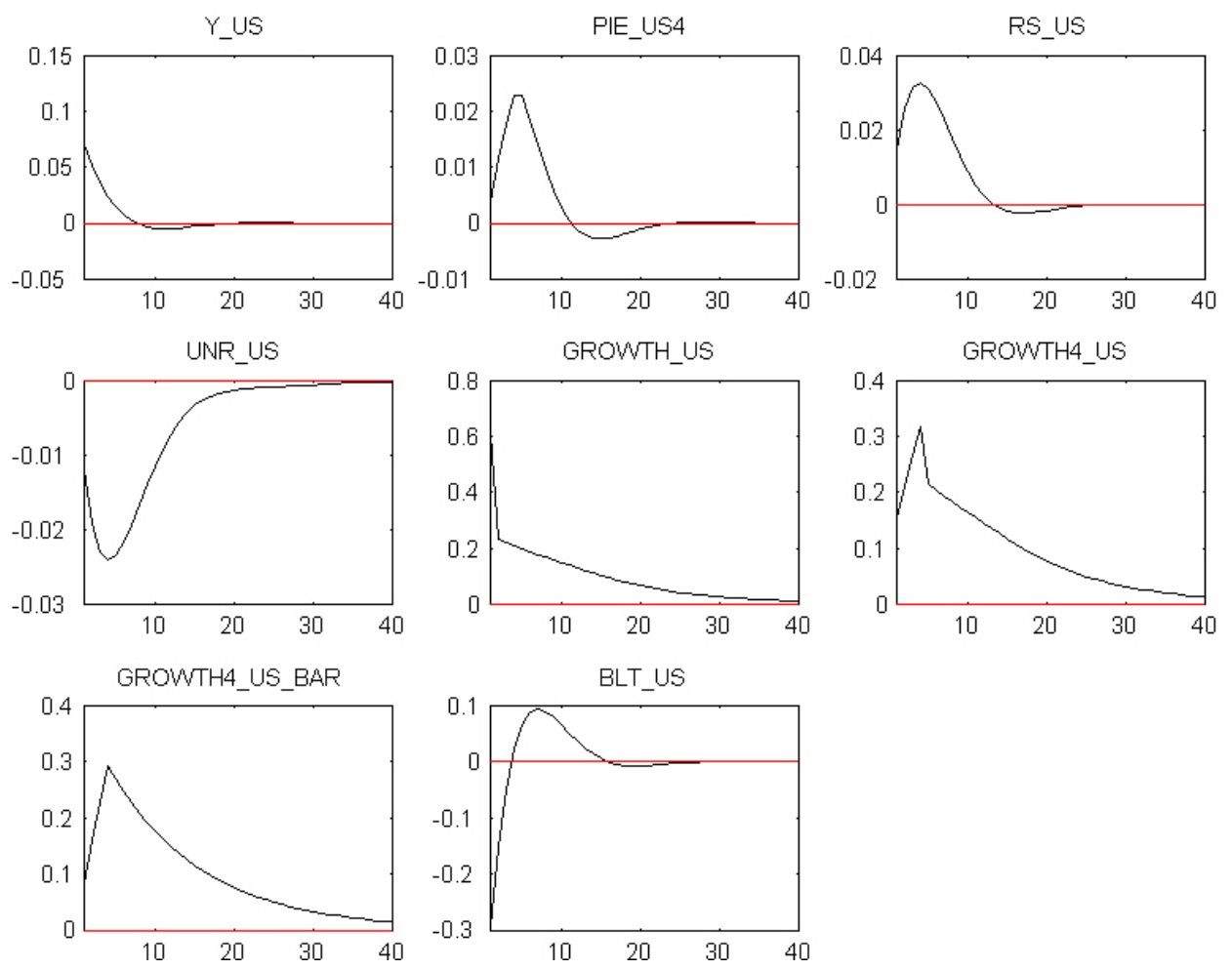
Figure 10: IRF Equilibrium GDP Level Shock $\left(\varepsilon_{u s}^{\bar{Y}}\right)$
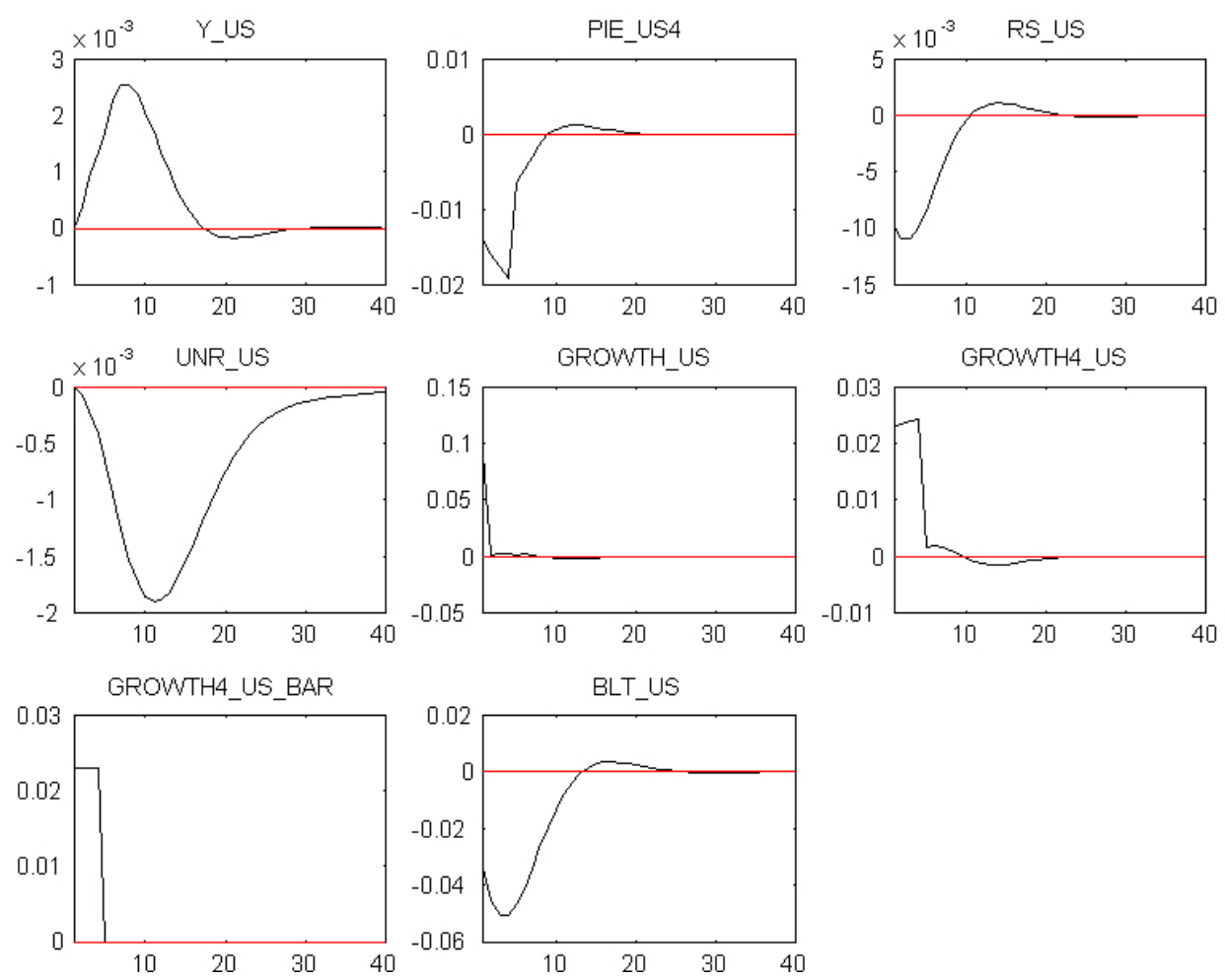
Table 7: BLT Root Mean Squared Errors

\begin{tabular}{l|lccc}
\hline \hline & 1 Q Ahead & 4 Q Ahead & 8 Q Ahead & 12 Q Ahead \\
\hline & 0.43 & 0.58 & 0.82 & 0.93 \\
$y_{u s}$ & 0.34 & 0.83 & 0.76 & 0.75 \\
$\pi 4_{u s}$ & 0.46 & 1.1 & 1.5 & 1.7 \\
$r s_{u s}$ & 0.15 & 0.39 & 0.68 & 0.9 \\
$U_{u s}$ & 0.31 & 0.37 & 0.46 & 0.53 \\
$\bar{U}_{u s}$ & 1.8 & 2 & 2.2 & 2.1 \\
$4\left(Y_{u s}-Y_{u s,-1}\right)$ & 0.54 & 1.2 & 1.6 & 1.5 \\
$Y_{u s}-Y_{u s,-4}$ & 0.32 & 0.61 & 0.88 & 1 \\
$\bar{Y}_{u s}-\bar{Y}_{u s,-4}$ & \multicolumn{4}{l}{} \\
\hline \hline
\end{tabular}


Table 8: Variance Decompositions

\begin{tabular}{lccccccc}
\hline & Mean & Std. Dev. & $\varepsilon^{r s}$ & $\varepsilon^{g^{\bar{U}}}$ & $\varepsilon^{y}$ & $\varepsilon^{\pi}$ & $\varepsilon^{B L T}$ \\
\hline & & & & & & & \\
$\mathrm{y}_{t}$ & 0.0 & 1.0 & 5 & 1 & 22 & 2 & 70 \\
$\pi_{t}$ & 2.5 & 1.6 & 2 & 0 & 2 & 75 & 22 \\
$\pi 4_{t}$ & 2.5 & 1.1 & 3 & 0 & 3 & 53 & 41 \\
$\mathrm{rs}_{t}$ & 4.3 & 1.6 & 13 & 0 & 3 & 10 & 73 \\
$4\left(\mathrm{Y}_{t}-\mathrm{Y}_{t-1}\right)$ & 2.6 & 2.1 & 3 & 21 & 52 & 0 & 24 \\
$\left(\mathrm{Y}_{t}-\mathrm{Y}_{t-4}\right)$ & 2.6 & 1.4 & 3 & 35 & 20 & 0 & 41 \\
$\mathrm{u}_{t}$ & 0.0 & 0.8 & 6 & 0 & 14 & 2 & 71 \\
& & & & & & & \\
& & & & & & & \\
\hline
\end{tabular}


Figure 11: Y-O-Y GDP Growth Rate Dynamic Forecast (Base Case Model) GROWTH4_US 8 periods ahead (2)

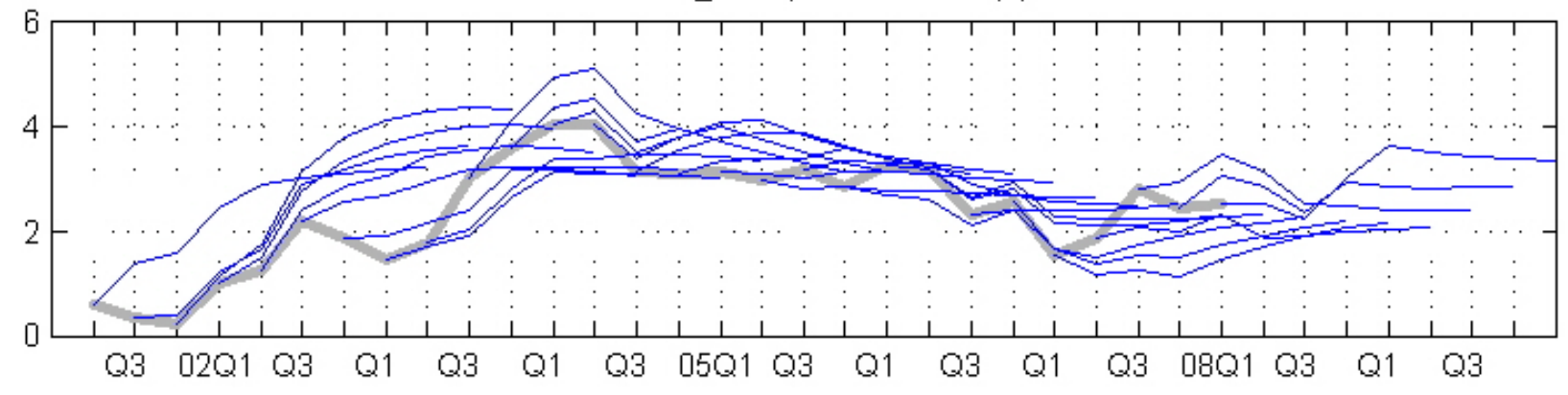

Figure 12: Y-O-Y GDP Growth Rate Dynamic Forecast (BLT Model) GROWTH4_US 8 periods ahead (2)

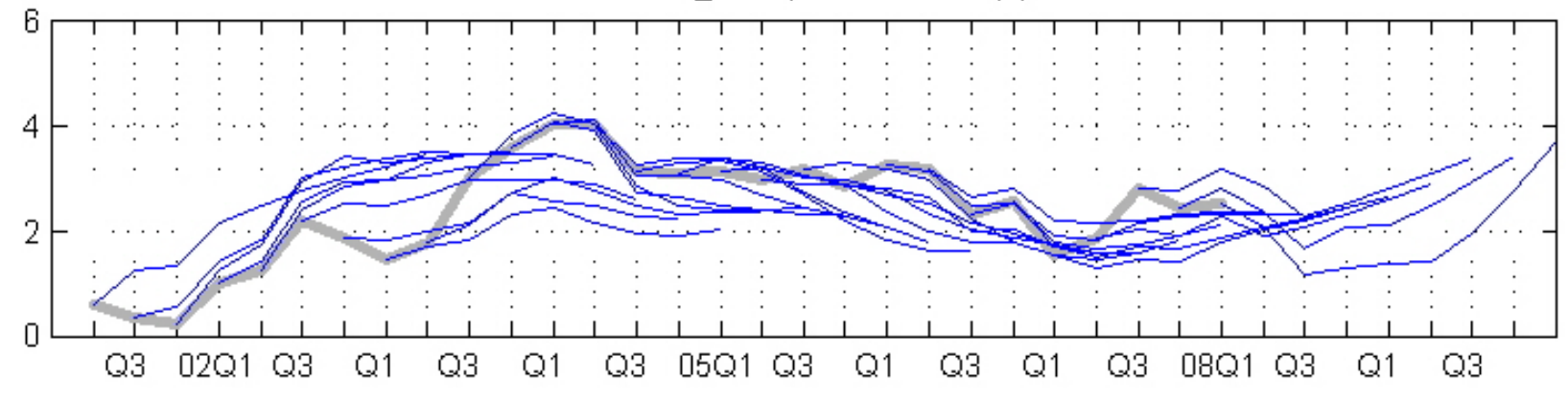


Figure 13: Q-O-Q GDP Growth Rate Dynamic Forecast (Base Case Model)

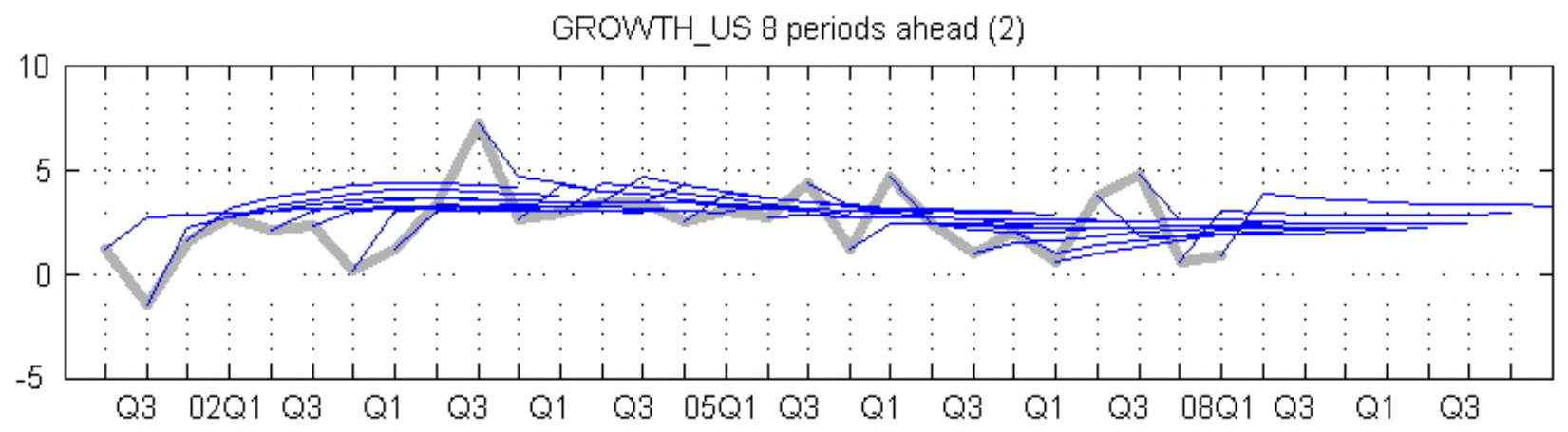

Figure 14: Q-O-Q GDP Growth Rate Dynamic Forecast (BLT Model)

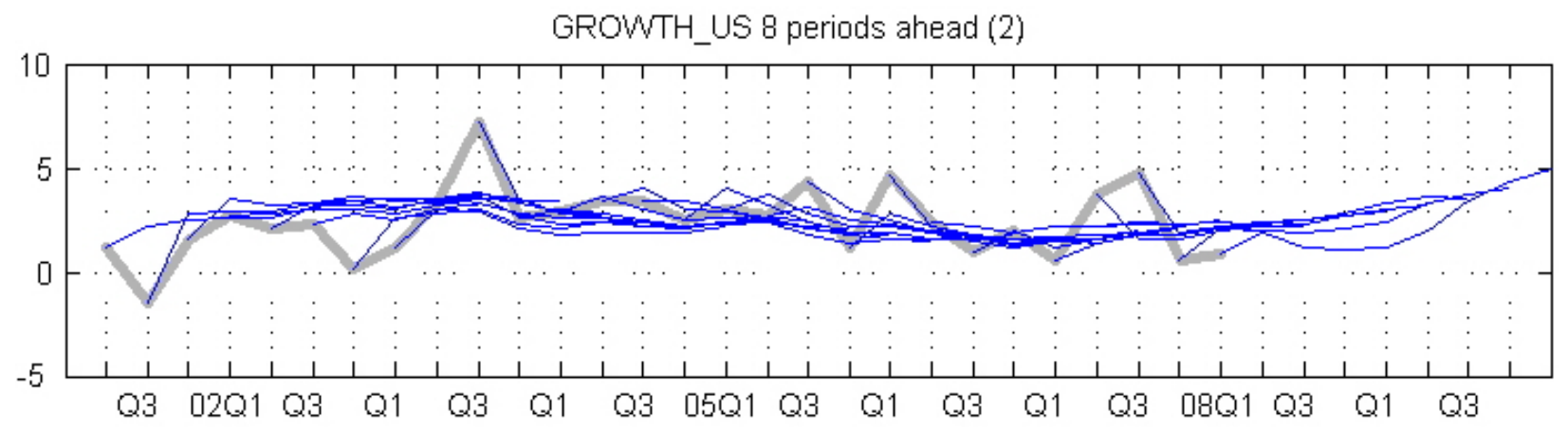


Figure 15: Inflation Dynamic Forecast (Base Case Model)

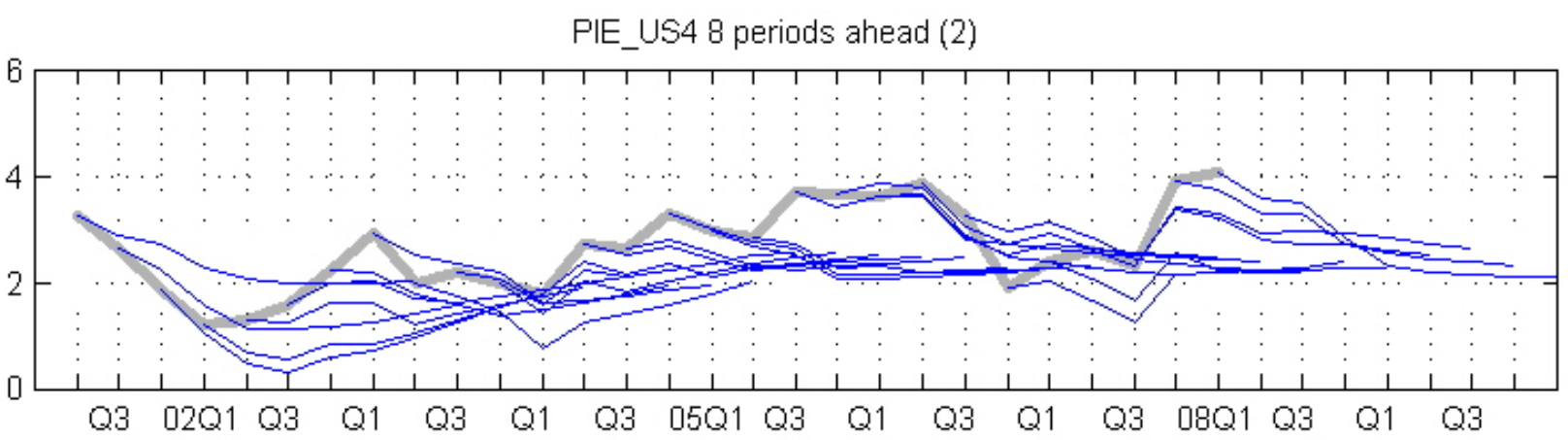

Figure 16: Inflation Dynamic Forecast (BLT Model)

PIE_US4 8 periods ahead (2)

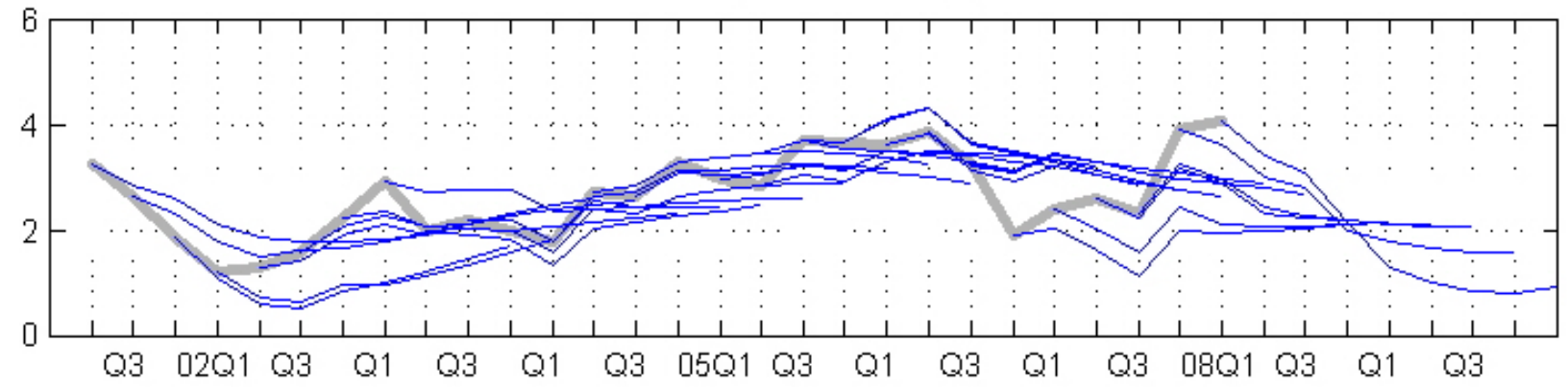


Figure 17: Interest Rate Dynamic Forecast (Base Case Model)

RS_US 8 periods ahead (2)

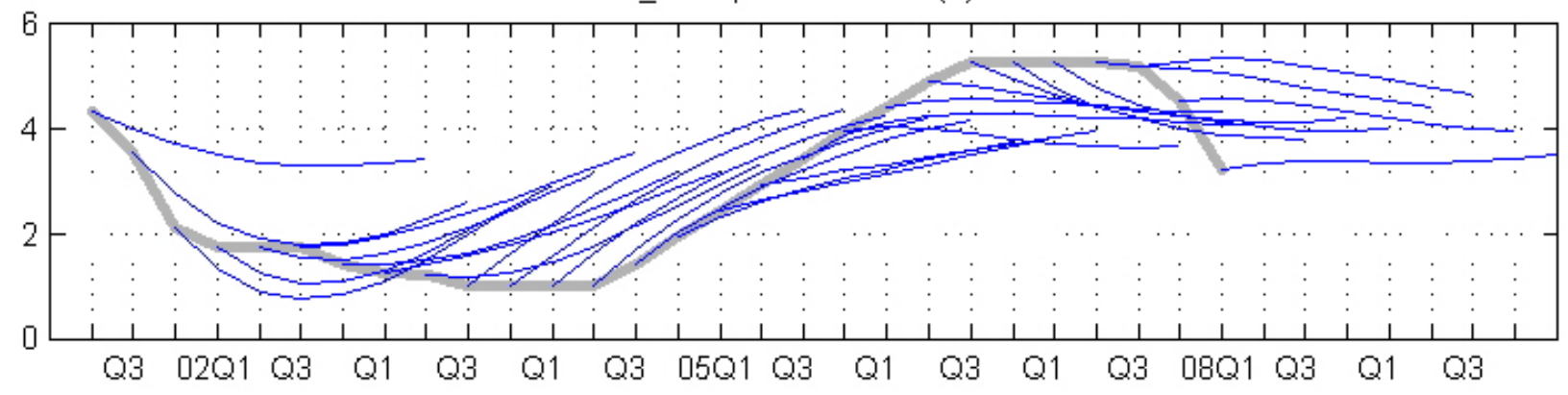

Figure 18: Interest Rate Dynamic Forecast (BLT Model)

RS_US 8 periods ahead (2)

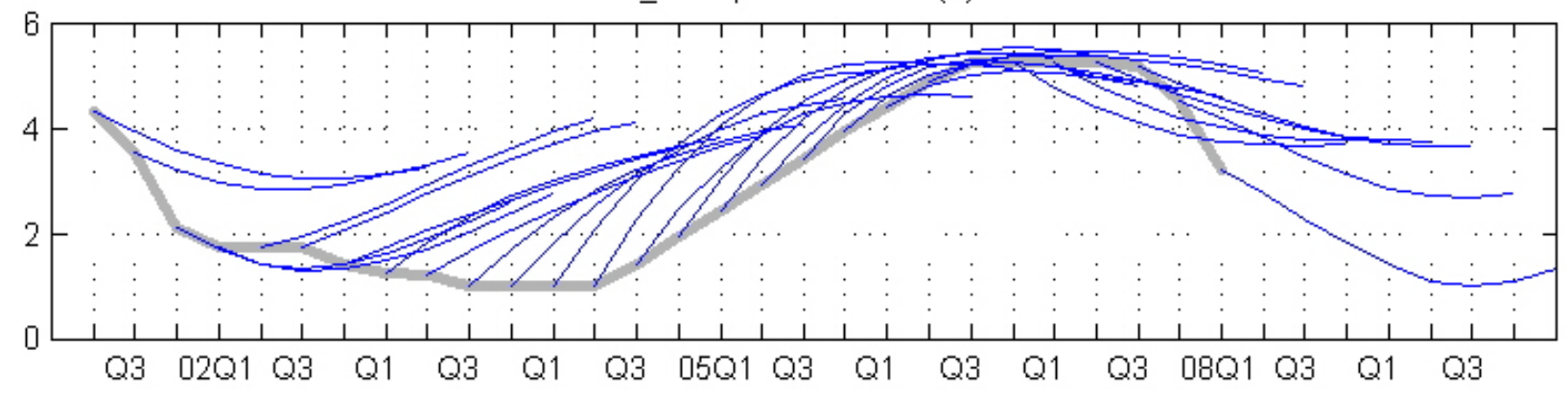


Figure 19: Unemployment Rate Dynamic Forecast (Base Case Model) UNR_US 8 periods ahead (2)

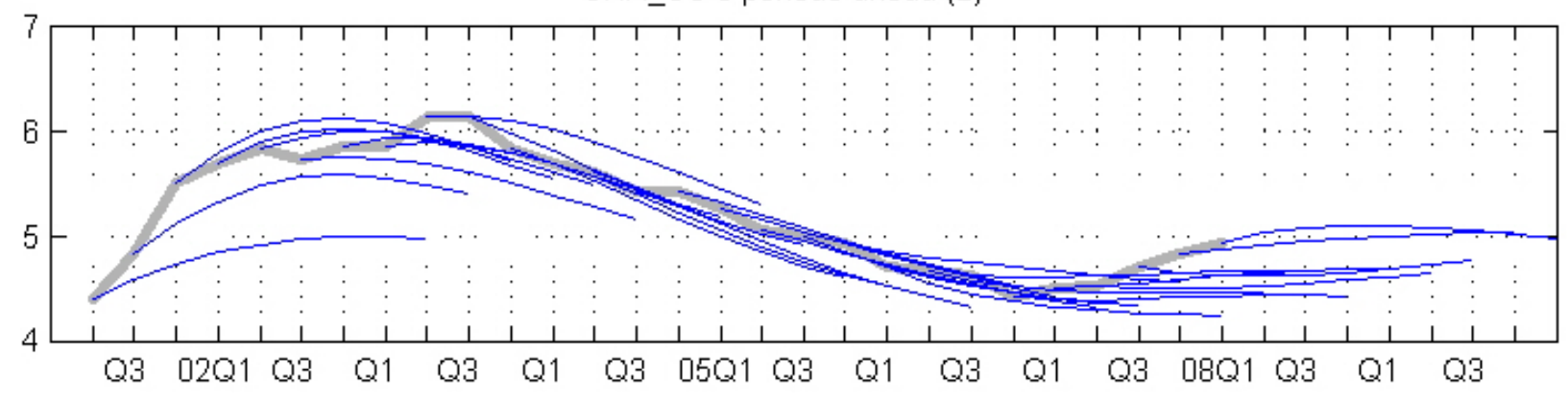

Figure 20: Unemployment Rate Dynamic Forecast (BLT Model)

UNR_US 8 periods ahead (2)

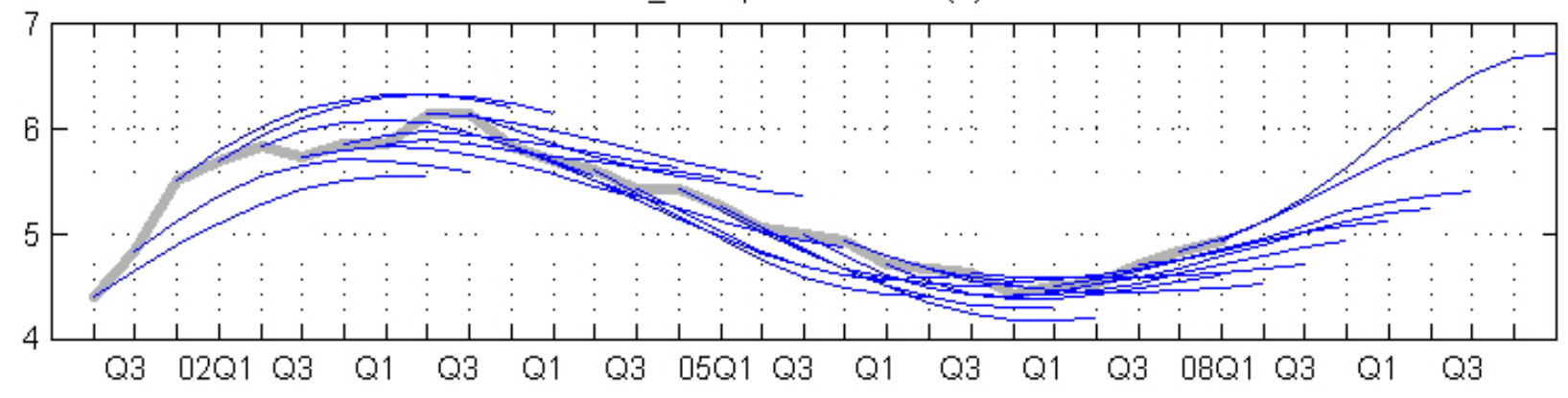


Figure 21: Output Gap Dynamic Forecast (Base Case Model)

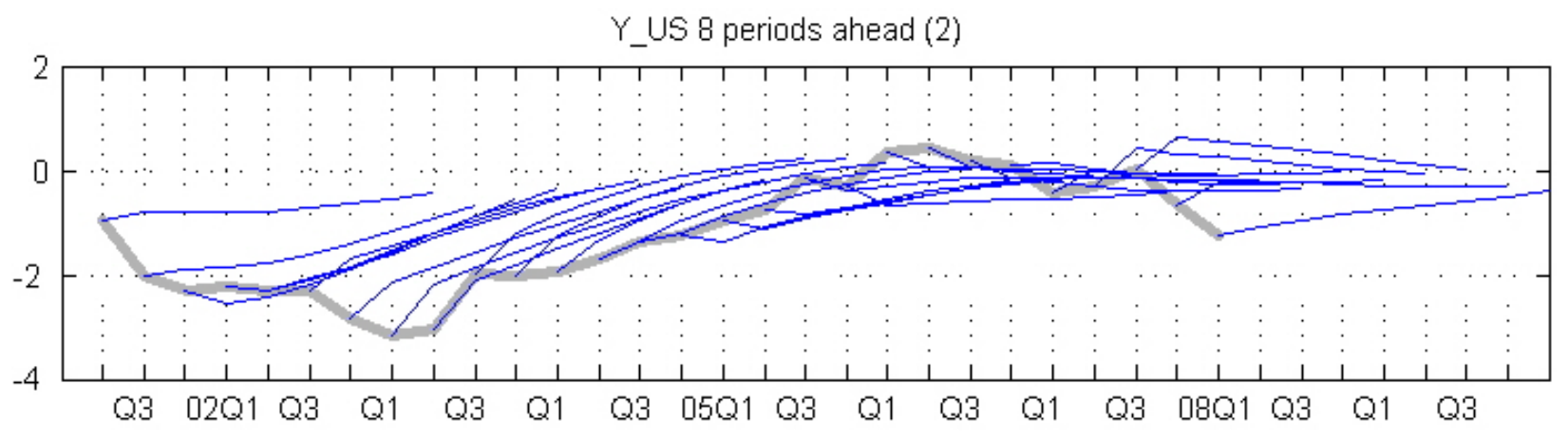

Figure 22: Output Gap Dynamic Forecast (BLT Model)

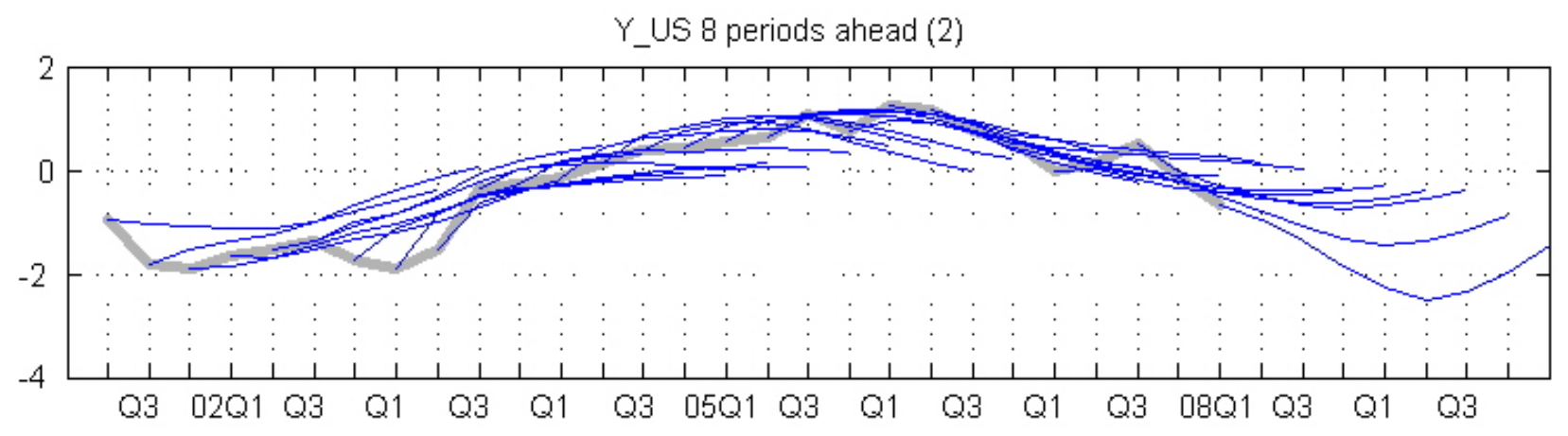

